\title{
Linking the actors and policies throughout the disaster management cycle by "Agreement on Objectives" - a new output-oriented management approach
}

\author{
S. Greiving ${ }^{1}$, S. Pratzler-Wanczura ${ }^{2}$, K. Sapountzaki ${ }^{3}$, F. Ferri ${ }^{4}$, P. Grifoni ${ }^{5}$, K. Firus ${ }^{6}$, and G. Xanthopoulos ${ }^{7}$ \\ ${ }^{1}$ TU Dortmund University, Dortmund, Germany \\ ${ }^{2}$ Institute for Fire Service and Rescue Technologies, Fire Department, Dortmund, Germany \\ ${ }^{3}$ Harokopio University of Athens, Athens, Greece \\ ${ }^{4}$ Istituto di Ricerche sulla Popolazione e le Politiche Sociali, CNR, Italy \\ ${ }^{5}$ Istituto di Ricerche sulla Popolazione e le Politiche Sociali, CNR, Italy \\ ${ }^{6} \mathrm{~T} 6$ Ecosystems srl, Italy \\ ${ }^{7}$ Institute of Mediterranean Forest Ecosystems and Forest, Greece \\ Correspondence to: S. Greiving (stefan.greiving@tu-dortmund.de)
}

Received: 29 July 2011 - Revised: 27 October 2011 - Accepted: 20 March 2012 - Published: 17 April 2012

\begin{abstract}
Current management of disaster risks is often fragmented due to a lack of coordination between involved actors, i.e. civil protection and spatial planning - a phenomenon which is known as the "problem of interplay". This paper presents an output-oriented risk management approach ("parametric governance"). Here, the modality of the achievement of objectives remains in the hands of the given addressees. This implies a shift from a top-down to a more collaborative, process-oriented form of decisionmaking. The approach has been successfully applied in two hazard cases and three administrative contexts: (a) the City of Dortmund (Germany) facing flash floods, (b) East Attica region (Greece) facing forest fires, and (c) Lazio Region (Italy) also facing forest fires. As proved by the applications of the concept, a dialogue among experts, stakeholders, and decision-makers is indispensable in order to guarantee inclusion of all diverse and competing values, opinions, and claims. Moreover, a structured communication path is needed to meet the requirements of a risk governance process. Finally, a win-win-situation among the involved actors has to be created to reach an agreement on common goals and actions to achieve them in due time.
\end{abstract}

\section{Introduction}

The reduction of disaster risk from multiple hazard sources is an explicitly pronounced aim in several international agendas, for example in the Agenda 21 (UN, 1992), the Johannesburg Plan (adopted at the 2002 World Summit on Sustainable Development) or the Hyogo Framework for Action (UN-ISDR, 2005). Strategies and actions to "control, reduce and transfer risks" on the basis of risk assessments and analyses can be subsumed under the term risk management (UN-ISDR, 2009). Linking the relevant actors and policies throughout the disaster management cycle, but also creating an inventory of information on disasters are propagated as key objectives by the EC Communication "A Community approach on the prevention of natural and man-made disasters" (EC, 2009). Here, it becomes clear that available knowledge on disasters is currently limited and suffers from a lack of comparability.

Furthermore, current prevention of risk caused by natural hazards is fragmented, among others, between civil protection and spatial planning (see e.g. Greiving et al., 2006; Sapountzaki et al., 2011) and consequently funding is also fragmented. This is a problematic situation because the Response-Preparedness-Prevention-Remediation (RPPR-) chain presupposes coordination between the involved actors, or one co-ordinating actor. However, the current, real situation is featured by processes where 


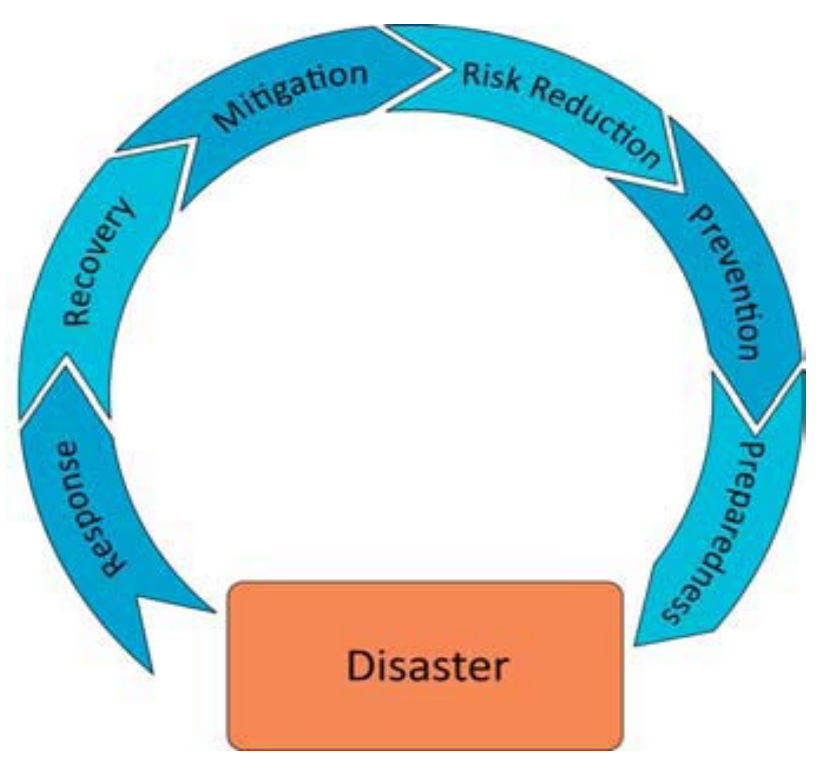

Fig. 1. Disaster management cycle (Source: own elaboration).

information, knowledge and activities run in parallel and there are no linkages among sectoral planning, spatial planning and emergency response. The imperative of coordination refers not only to prevention/preparedness measures but covers also preparations for the remediation phase because the remediation stage functions simultaneously as the prevention stage for the next disaster event (see Fig. 1). Administrative fragmentation, however, complicates and/or prevents co-ordination of activities. This is not an effective and efficient way to deal with risk, especially in times of/before hazardous events because fragmentation and lack of coordination lead among others to lack of specific responsibility and duplicated activities (Wanczura, 2010). These problems imply huge, inefficient, and ineffective resource consumption, a key-issue in times of limited (financial, personnel etc.) resources. To avoid this and provide more flexibility and better coordination, the disaster risk community agrees on the need of an integrated response strategy to disasters, covering the whole RPPR-chain, in order to create resilient communities (see Sapountzaki et al., 2011).

To the above end, the European INCA Project ("Linking civil protection and planning by agreement on objectives") co-financed by the Civil Protection Financial Instrument of the European Community - was launched in 2009. It aimed at bridging spatial, functional and operational gaps and divergences in approach, competence, and perspective between civil protection, spatial planning, and other administrations in charge of prevention, by a collaborative process with concrete results to make measures and actions of risk prevention and mitigation efficient, effective, strategically aligned, and sustainable (see also Sapountzaki et al., 2011). The authors of this paper represent the project team of INCA and were responsible for all three case studies which are presented in Sect. 6.

The starting point for an alternative approach was the analysis of the state-of-art in three selected case study areas (East Attica Region, Greece; Lazio Region, Italy; City of Dortmund, Germany). The situation of each case study was analysed by means of literature research and expert interviews, considering all involved actors: civil protection, sectoral planning, and spatial planning. The analysis confirmed (a) the problem of lack of coordination between policies and actors with joint competence for risk management and (b) a minor or no role at all for spatial planning in risk management (Sapountzaki et al., 2011). There was a mutual understating of these problems among all actors which has to be seen as the crucial starting point for implementing a collaborative process, because the genuine interests of organisations to gain more power often intervenes collaborative processes. However, improving the inter-organisational coordination through the intended agreement on common objectives was seen by all actors as a win-win-situation due to the given shortcomings of the management practices regarding their own agenda. The outcome was structured along a SWOT-Analysis (Strengths, Weaknesses, Opportunities and Threats) for several elements of the RPPR-chain. This analysis served as an initial point for the concept of "Agreements on Objectives" of risk prevention and damage mitigation that integrates non-structural and structural risk mitigation activities, offering a practical, goal-oriented, consensual alternative to the more rigid and restrictive strategies of both planning and civil protection. The concept aims at more efficiency and flexibility in risk prevention and response actions.

\section{State-of-the-art in the field of theoretical methods of (risk) coordination, communication and governance}

The concept of risk governance has been created and evolved in the area of new, emerging, mostly man-made risks. Nonetheless, it is of particular relevance also for natural hazards. Actually the successful management of natural hazards is limited, due to the fact that the interactions between individual sectors, disciplines, locations, levels of decision-making, and cultures are not known or not considered (IRGC, 2005; Greiving et al., 2006). Inadequate public available information about risks in terms of societal and natural dimensions, inapprehensible procedural steps as well as insufficient involvement of the public in the risk-related decision-making process lead to severe criticism and distrust.

Furthermore, decisions in the area of so called "traditional" hazards such as floods or mass movements, taken mainly on the basis of engineering expertise, are normally based on probabilities because they are mainly past-oriented and informed by statistics. However, analysed data are only available for a specific period and are thus not representative for longer periods. This problem is even enlarged by the 
observed climate change- related effects on temperature and precipitation which will certainly lead to new uncertainties, because past events might be not representative anymore. Additionally, changes in the catchments (e.g. deforestation, melting of glaciers, surface sealing through settlement development, etc.) will lead to even higher uncertainties. For new "uncertain" risks (see before), however, the perspective changes in tendency from probability to possibility. These are characterised by possible, new, imaginable hazards, unknown coupling of processes, no or limited experience, complex causalities, multiple, heterogeneous and long-term effects. Therefore, there is no scientific or historic proof but they cannot be fully refuted either. The role of science in this context is problematic because science cannot give a proof of risk and cannot guarantee for safety. Science in this context is inconclusive (van Asselt, 2005). With public decisionmaking not having any precise statistical information at hand, restrictions imposed on private property rights are probably not legally justifiable anymore. Hereby, justification of actions and consensus about thresholds for acceptable risks and response actions becomes more important.

Within the global change debate, the field of climate change in general, but particularly as a triggering factor for many natural hazards, is of special importance for Europe with its existing settlement structures, cultural landscapes and infrastructures which have been developed over centuries. Land ownership, administrational and political frameworks in Europe are very complex. Moreover, several hazard-prone areas in Europe have only been settled recently. However, prevention actions carried out i.e. by spatial planning are nonetheless less effective than in countries which are still growing rapidly in terms of population and the built environment. Here, disaster prone areas can be more easily kept free from further development whereas many more of these areas in Europe are already built-up. This calls for authorities to improve public risk awareness and to look for means to mitigate this problem. Moreover, measures based on mandatory decisions of public administration as well as measures which are in the responsibility of private owners need to be understood and regarded as suitable by their addressees so as to guarantee their implementation. This is clearly visible when looking at evacuation orders or building protection measures to be taken by private households. Having these facts in mind, the "active involvement" of the population at risk is crucial for successful risk management and its ultimate goal: the reduction of risks. This is propagated for instance by the European Communities Flood Management Directive (European Communities, 2007). Within the European Community, it has been recognized as well that this approach also has to be applied to other natural hazards such as coastal hazards or soil erosion and landslide hazards (e.g. European Commission, 2006).

Risk governance has become increasingly politicised and contentious. The main reasons are controversies concerning risk that are not about suitable scientific methodologies for hazard and risk assessment (Armaş and Avram, 2009). Rather, risk controversies are disputes about who will define risk in view of existing ambiguity. In many cases policy discourse is not about who is correct about assessment of danger, but whose assumptions about political, social, and economic conditions as well as natural or technological forces win in the risk assessment debate. Thus, the hazard as a potentially damaging physical event is real, but risk is socially constructed.

Scientific literacy and public education are important but are not the only aspects necessary to avoid conflicts about risk. Emotional response by stakeholders to issues of risk is truly influenced by distrust in public risk assessment as well as in risk management. Due to this fact, those who manage and communicate risks to the public need to understand the emotional responses towards risk and the way risk is perceived by the at-risk population. It is a matter of the definition of risk how risk policy is carried out. Moreover, defining risk is an expression of power. Slovic (1999) thereby argues that whoever controls the definition of risk, controls risk policy. Within the communication strategies in all approaches, trust, transparency, clarity, and confidentiality can be seen as central terms in this respect (Löfstedt, 2005; IRGC, 2009; Greiving, 2009a).

Another deficit in current risk management relates to the lack of coordination between actors involved in the disaster risk cycle as outlined by the EC Communication on "A Community approach on the prevention of natural and manmade disasters" (European Communities, 2009). According to Meadowcroft (2002), it has to be pointed out that "there are many inconsistencies in this formal hierarchy of scale. [...] And territorially rooted institutions are constantly being stretched to engage with issues which escape their jurisdiction or infiltrate their frontiers." Other authors highlighted that the effectiveness of the implementation of an EU-directive depends in the first instance on the fitting of the directives approach (here: the water basin approach) to the existing institutional arrangements (Knill and Lenschow, 2000). In this context, research on the institutional dimensions of environmental change has identified "cutting-edge" themes. Young (2002) gives a closer description:

- Problem of fit: the problem of fit deals with congruence or compatibility between ecosystems and institutional arrangements created to manage human activities affecting these systems. Overall, the presumption is that the closer the fit between ecosystems and institutional systems, the better the relevant institutions will perform;

- Problem of interplay: most institutions interact with other similar arrangements both horizontally and vertically. Horizontal interactions occur at the same level of social organisation. Vertical interplay is a result of cross-scale interactions or links, involving institutions located at different levels of social organisation. Interplay between or among institutions may take the form of 
functional interdependencies or arise as a consequence of politics of institutional design and management. The problem of interplay is a consequence of the existence of a multitude of actors.

Thus, any coordination of activities has to regard this fragmentation of responsibilities. These problems related to organisational capacities for responding to or monitoring risk have been also pointed out as major deficits of current risk governance (IRGC, 2009).

\section{Change of traditional government into output-oriented governance: The "Agreement on Objectives" approach and its implementation}

During the last years, the understanding of the role of government has been changed from a traditional approach where the state itself provides all kinds of public services to a model which is characterised mainly by private services, while the state only guarantees the quality of those services which are of public interest (Johnson, 1991; Neary, 2001). One important reason can be seen in the lack of financial resources and the alteration of classical hierarchical government: the addressees have control of important resources (e.g. information, creativity, knowledge, etc.) not only in connection to risk-related issues. Further, fewer and fewer standardised solutions can be purported to manage the given situation, (e.g. of existing risk etc.). Therefore, the state switches to bilateral-cooperative forms of governance, where the addressees concentrate on new, appropriate solutions and targets as well as output-oriented governance (summarised under the term "Agreement on Objectives" or "parametric governance"). This approach aims at governance via parameters or requirements. Here, the modality of the achievement of objectives remains in the hands of the given addressees (Cools et al., 2003).

Risk governance can involve large and complex organisations at different levels. Large organisations such as city governments are complex, with a diversity of departments, stakeholders, resources, constituents, and issues. They operate in the context of ever-changing conditions and capabilities that are difficult to identify, so leveraging them into practical, swift coordinated action is not an easy task when mainly using traditional models that address political and administrative systems, and reflecting all the coordination and perception problems produced by those models. To find an appropriate model that supports the tasks connected to risk governance is seen as an enormous challenge. There is a need for a model based on an output-oriented process, i.e. a model that can be simultaneously applied at continental, national, and local levels. Therefore, the authors have elaborated a model that is based on a government process designed to manage the risk problem as it arises in the territory under consideration. This approach, differently from the traditional and conventional ones - where the risk management process is adjusted to the legal-administrative system which puts it into practice (input oriented model) - adapts the administering structure to the risk features and problems. This represents a very innovative perspective and opens wide horizons regarding future modes of operation of public administrations, authorities, and stakeholders not only in the field of risk management but also in other policy fields, using the approach of "Agreement on Objectives" described more in detail in the following sections.

Such output-oriented management approaches have been widely used for decades in new public management (Lane, 2000), but also comprehensive city marketing concepts (Paddison, 1993). Up to now they are not common in disaster risk management although there are several similarities such as a need for coordination of actions of different autonomous actors, common objectives and evaluating the effects of the chosen measures. This justifies an application test of an output-oriented management approach to risk management of natural hazards.

The process of the "Agreement on Objectives" is characterised by three blocks: "Output", "Impact", and "Outcome". "Output" is the first stage of the process described in Fig. 2. Here, a given organisation supplies the necessary financial resources available to the addressees for the realisation of a given objective. According to Krems (2007), "Impact" can be seen as the reaction (i.e. contribution) of the addressees to the output. In our case these are the actions that the funding aims to achieve. "Outcome" is seen as the result of output, (e.g. effects of the output concerning the political objectives) or more generally speaking, it is the longterm situation aimed at that is described through the project objectives (Haering et al., 2002).

In connection to this, there are some instruments (suggested by Haering et al., 2002) to control the whole process of "Agreement on Objectives":

- At the strategic level - which means the agreement on an overarching goal principally possible at every spatial level - the question arises of whether the agreed objectives contribute to the desired outcome (reduction of the given risk). Therefore "Monitoring" and "Evaluation" are necessary instruments to control the obtained effects as well as to evaluate the entire program (see Fig. 1). These should be located at the appropriate (regional or national) level.

- At the operational level, the performance of single measures contributing to the overarching goal, the systematic examination as well as the assurance of implementation of the agreed objectives are of major importance. For this purpose "Controlling" can be used. It is a process which covers both observation (retrospective) and planning (prospective). It belongs to the responsibility of the participants/addressees. They decide on the mitigation measures, and accordingly implement the given 


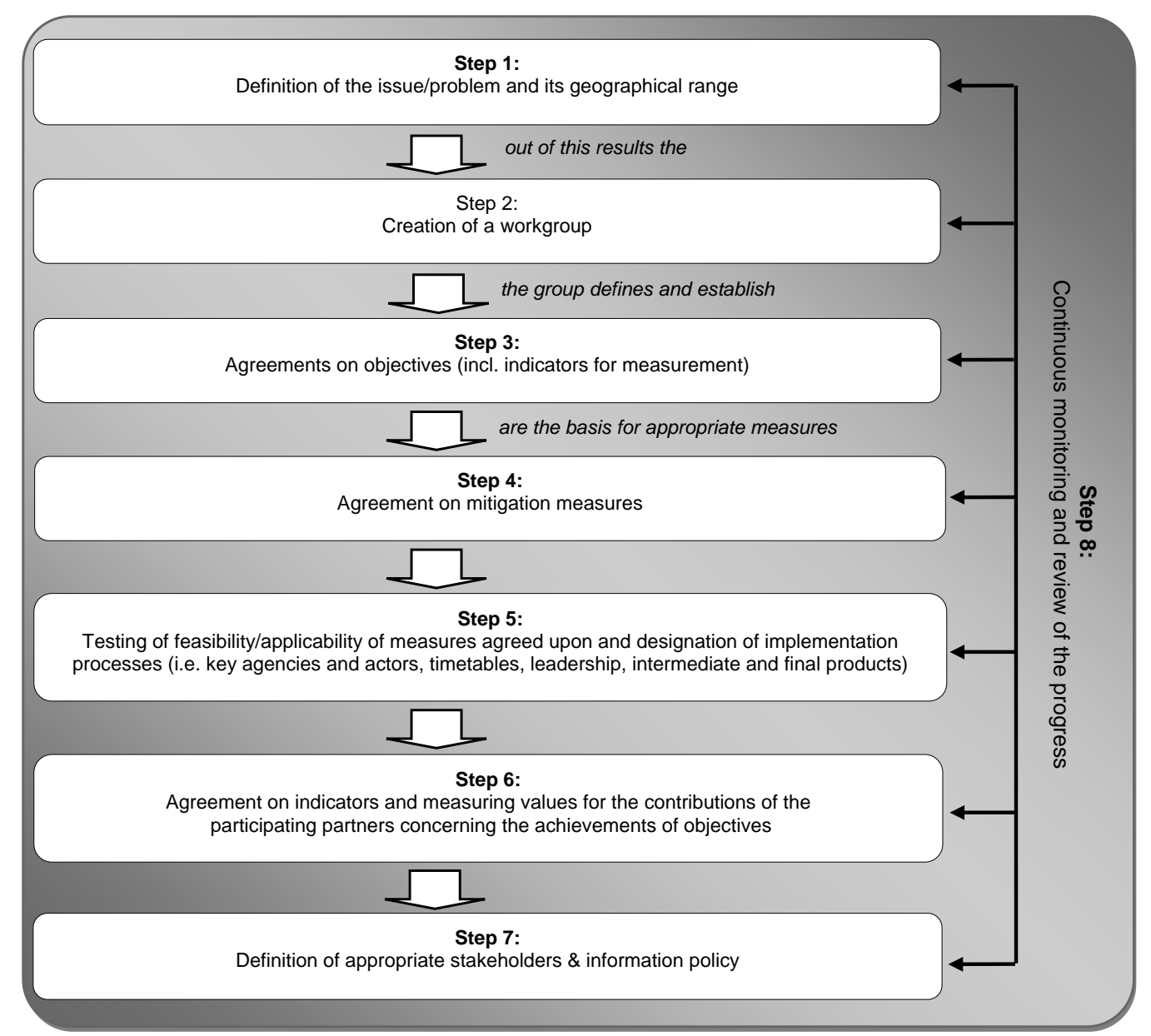

Fig. 2. Agreement on objectives: Step-by-Step (Source: own elaboration).

objectives and detect the actual values on results. This means that they control the effects (outcome) of the mitigation measures. Finally, the comparison of the targeted and actual objectives has to be done in order to know how far the objective has been achieved. In case of large deviations the mitigation measure or the objective has to be reviewed and adapted, and the planning cycle has to start again. In this context the dynamics of the given risk as well as other circumstances such as the available resources should be taken into account.

One of the central components of an "Agreement on Objectives" is a kind of "product sheet" (see Table 1). This product sheet can be seen as the central component or a treaty (as a possible outcome of the "Agreement on Objectives") between the participating groups. It comprises the agreed objectives and the contributions and/or achievements of the contracting parties.

To sum it up, the "Agreement on Objectives" is characterised by flexibility and the possibility of a large variety of solutions that lead to greater motivation and implementation capacity of all involved actors (Cools et al., 2003). Furthermore, it offers elbow room to the addressees and has comparative advantages:

- the governance authority has a wide range of choices with regard to the instruments that can be used for the implementation of the objectives (opportunities for sanctions, stimulations etc.);

- the targeted objectives are not too complex and can become operational with the help of one or more parameters;

- the overall objectives are split and the distinct components are incorporated into the objectives of the addressees, or the communication between the governance authority and the addressee is designed in a distinctive way, that allows consensus on common objectives;

- the "Agreement on Objectives" can be applied (in principle) at all levels of the planning system. 
Table 1. Product sheet of an "Agreement on Objectives" (Source: according to Haering et al., 2002).

\begin{tabular}{|c|c|}
\hline Element & Description \\
\hline Objective & Description of the intended outcome \\
\hline Effect-oriented goal & Description of the intended effects \\
\hline Monitoring indicators & Indicators for monitoring of the intended outcome \\
\hline Product characteristics & Description of basic information (legal framework, focused clientele etc.) \\
\hline Treaty goals & Contributions of the different partners to the intended outcome \\
\hline Controlling indicators & $\begin{array}{l}\text { Indicators for controlling of the implementation and effects of the different } \\
\text { contributions (each treaty goal will be measured with a quantitative indicator) }\end{array}$ \\
\hline Quality control & Definition of quality goals such as best available technology or code of behaviour \\
\hline Financing & Cost unit for each of the treaty-goals \\
\hline
\end{tabular}

In comparison to traditional, input-oriented decision-making, the "Agreement on Objectives" offers more flexibility. It is an alternative process to the fragmented management of risks and can be seen as a "win-win situation" for all included partners, authorities, institutions, etc. especially under circumstances of rapid change and uncertainty (Fischhoff et al., 1978; Wanczura et al., 2007; Wanczura, 2010). Under such circumstances it is hardly possible to provide comprehensive decision criteria. So, hierarchic and static rules as well as frames are not sufficient for dealing with rapidly changing conditions and consensus becomes the only justifiable basis for decisions. From this perspective, negotiations between the different authorities can be seen as the only unfaltering way to achieve "Agreement on Objectives". Indeed negotiations might render convergence of different interests and values on common interest issues.

Considering it from the perspective of spatial planning in particular, the "Agreement on Objectives" is even more important. This approach is a good solution for the changing role of (spatial) planning and the tasks spatial planning is responsible for. The aim is agreement on objectives between spatially relevant actors (authorities) when dealing with risks, for instance. It is obvious that existing spatial plans are not very effective in achieving this aim because policy priorities and measures are non-specific in terms of potential contributions and concrete results. As such these measures exert only minor or indirect pressure upon private actors (Cools et al., 2003; Greiving, 2009b).

As a response to the lack of financial resources and the critics upon the old subsidy approach, the concept of "Agreement on Objectives" offers an alternative. In this new approach, single, input-oriented projects (those which are subsidised in the lack of consideration of subsidies' effects and outcome) are replaced by output-oriented agreements connected with quantified effect- and output-requirements. The old subsidy approach based on financial support of technical risk protection measures paid only little attention to costefficiency. Furthermore, the conventional approaches lacked altogether a strategic and comprehensive perspective. In contrast to the past, the "Agreement on Objectives" focuses on the output and from a comprehensive point of view, too. An advantage of the concept is that the mode of achievement of objectives remains in the hands of the given addressees. Furthermore, since agreements concerning the output have been made, the regional and local participants receive more scope of action (Greiving, 2009b). These are important aspects because successful projects (also in the scope of risk management) - according to Osborne and Gaebler (1992) - are those which provide better quality and results for less money by cutting down unnecessary regulations and creating opportunities for creative solutions and cooperation.

Besides the agreement on one leading objective (or package of objectives), a further challenge is seen in the definition of appropriate, relevant, and practicable mitigation measures, as well as indicators to measure the fulfilment of goals and a potential treaty (as mentioned above). However, the indicators and measuring values have to perform monitoring of goals, implementation of measures and partners' contributions in a reliable, precise and unerring way (Cools et al., 2003).

\section{Indicators as standing instruments of evaluation}

The Guide Note on Indicators for Assessing Progress on Disaster Risk Reduction (UN-ISDR, 2007) defines indicators as "An explicit measure used to determine progress; a signal that reveals progress towards objectives; a means of measuring what actually happens against what has been planned in terms of quality, quantity and timeliness." (International Development Research Centre quoted in UN-ISDR, 2007). Thus indicators aim at the measurement of how far/well a programme/concept is achieving its given objectives. They define how performance is measured along a scale or dimension. In general it is possible to distinguish between qualitative and quantitative indicators. Independent of the kind of indicator, there are some requirements offered in the literature concerning general characteristics of indicators to ensure they will be useful as well as effective (Audit Commission, 2000). There are numerous challenges, having crucial effects on the realisation of an indicator system and the work with 
indicators. In the following the most important challenges are discussed.

Selecting appropriate and useful indicators, "is a fairly straightforward process, but requires careful thought, iterative refining, collaboration, and consensus-building" (USAID Centre for Development Information and Evaluation, 1996). Especially collaboration and consensus-building in order to create commonly acceptable decisions is quite problematic in times where different aims and priorities exist and risk management is often of secondary importance in relation to problems as e.g. unemployment, population loss, infrastructure shortages, etc. (Greiving et al., 2006). Consequently, the selection of appropriate indicators could be very problematic and could lead on the one hand to difficult discussions and on the other hand to a failure of the system.

Another challenge is the formal selection of suitable indicators. Shavelson et al. (1991) underlined that, "No indicator system could accommodate all of the potentially important indicators identified by such a comprehensive process and still remain manageable. The second step, then, is to develop a valid, useful, and parsimonious set of indicators. The purposes the indicator system serves (e.g. description of trends, information for accountability purposes) constitute one criterion for reducing the initial pool of potential indicators. System designers need to consult potential users to determine what those purposes should be, because the purposes will dictate the type of information that must be collected and the level to which it should be disaggregated."

Additionally Shavelson et al. (1991) annotate that some difficulties exist regarding the application of the characteristic criteria mentioned above. The most important aspect is that some highly desirable indicators, "may have to be eliminated because they cannot be measured reliably." That means that not sufficiently developed indicators to be included into an indicator system should be part of a developmental research agenda. One example is the vulnerability of the environment which often cannot be measured at all. Once the indicators meet the criteria of the responsible authority, they can be incorporated into the given indicator system.

The next task is linked with requirements: "Many data collection efforts and analyses will fall short of indicator requirements. Some of the most important potential indicators may not be measured at all and well-known difficulties with existing datasets are likely to constrain the analyses that indicators require. In many cases, sample sizes or designs will not be adequate for disaggregating data by groups of interest; some will not permit relational analyses among various components of the system. It is important to identify the shortcomings in existing data and analyses, and where these gaps and inconsistencies exist, to specify what work is needed to obtain reliable, valid, and useful indicators." (Shavelson et al., 1991)
All these mentioned challenges were considered in the elaboration process as well as the application of the indicator system of the "Agreement on Objectives" concept.

\section{Supporting instrument: "Road Map" for a guided process}

As mentioned in the introduction, the "Agreement on Objectives" concept is an approach bridging spatial, functional, and operational gaps as well as divergences in approach, competence, and perspective between civil protection, spatial planning, and other administrations in charge of prevention. The collaborative process that has been built for this purpose is based on the concept of "Agreement on Objectives" of risk prevention and damage mitigation (see Sect. 3). The process integrates non-structural and structural risk prevention and mitigation activities, offering a practical, goal-oriented, consensual alternative to the more rigid and restrictive spatial plans.

The concept is envisaged to lead to more efficient regional governance and flexibility in local risk prevention and response actions. It is transferable to all spatial levels for all hazard types and for all European countries. Its wide application is expected to lead also to more structured and efficient ways in coping with extreme events in transboundary territories. The step-by-step application ("Road Map") of the Concept as presented in Fig. 3 is adaptable to every specific place and particular risk problem. This is indeed confirmed by the three test cases (see Sect. 6). It should be kept in mind that the elaboration of a successful concept asks for an efficient and goal-oriented analysis of the current weaknesses and main deficits in the practice of public administrations in dealing with natural hazards in the selected case studies. The procedure used here is partly reminiscent of the process/methodology used within SWOT-Analysis, where the responsible authorities (i.e. stakeholders) discuss about the state-of-the-art of the given management of dealing with risks. Speaking in general: SWOT-Analysis is a strategic planning tool used for understanding and evaluation of strengths (S), weaknesses (W), opportunities (O) and threats (T) that are involved in an institution, project or whenever a situation requires a decision (i.e. also valid for dealing with risks).

According to Recklies (2005) the objective of the SWOTAnalysis is to determine to what degree the actual strategy is suitable and appropriate to meet the challenges and changes in the environment of the organisation and/or institution (or: dealing with a given risk). Concerning the topic discussed above it is obvious that the current way of dealing with risk is not satisfactory, so a change/adaptation of the strategy is necessary.

The elements of SWOT-Analysis can be characterised in four spheres as follows: 

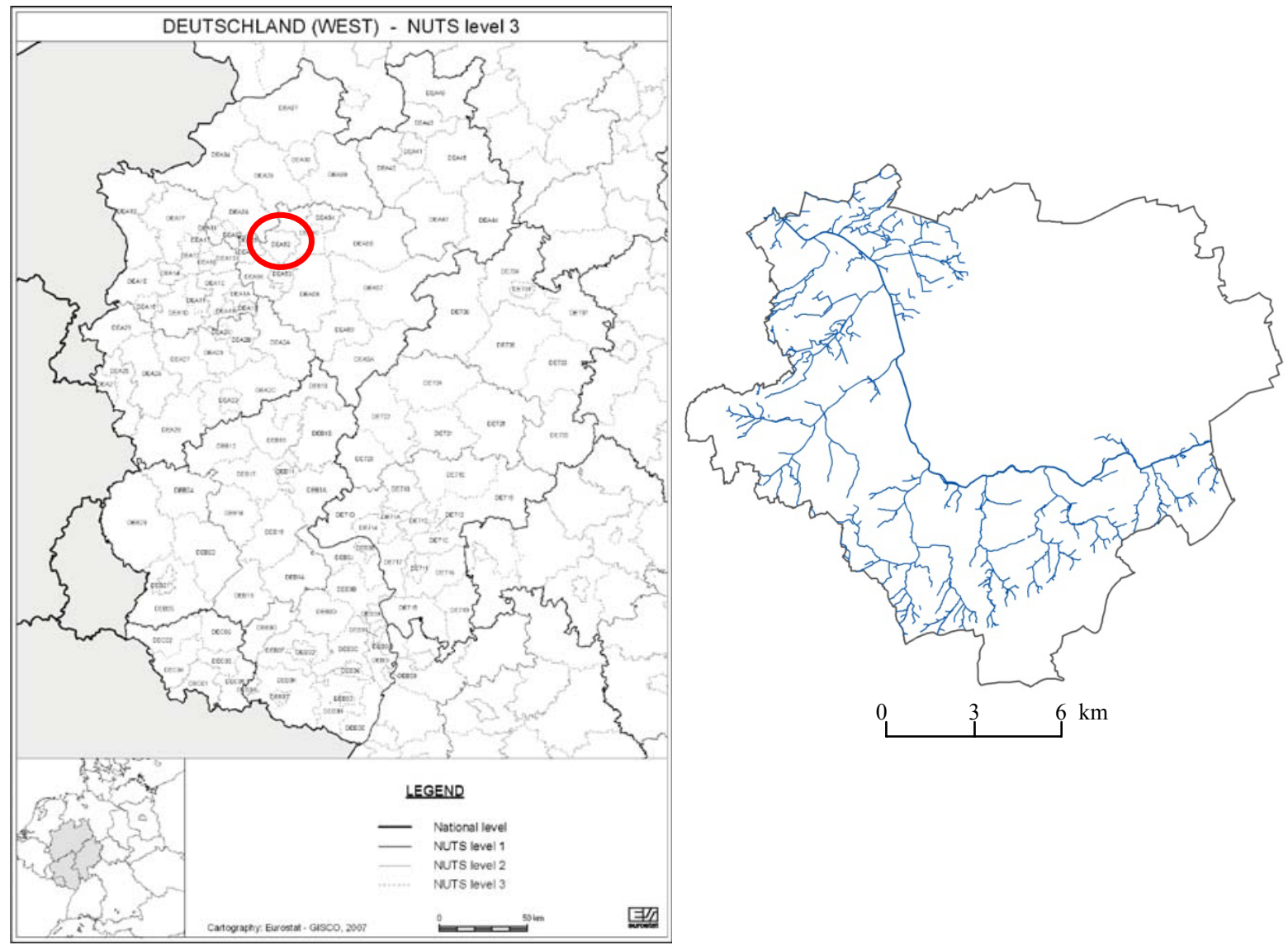

Fig. 3. Location of Dortmund in Germany (left; Source: Eurostat, 2007), "Emscher" River and its tributaries inside the city boundaries (right; own elaboration).

- Strengths: attributes of the process which are helpful to achieving the given objective;

- Weaknesses: attributes of the process which are harmful to achieving the objective;

- Opportunities: external conditions which are helpful to achieving the objective (potential favourable conditions);

- Threats: external conditions which could do damage to the performance (potential unfavourable conditions) (for more information see Blake et al., 2005).

These key-aspects of SWOT-Analysis were taken into account during the elaboration and work with the Road Map that will be presented in the following sub-chapters.

Step 1: Definition of the issue/problem and its geographical range

Before starting with resolving the problem of a given risk, it is important and necessary to frame the problem. What should be achieved (especially in the long-term)? What would be an optimal way of dealing with this risk? What is the geographical range of the risk, (i.e. is it a local or a regional problem)? Defining the overall vision, mission, priorities, and goals with regard to the specific risk is the focus of this first step and the prerequisite to find/define appropriate strategies to solve the problem. This first step is up to those actors who initiative the process. IT could either be a representative of a planning or civil protection authority.

Step 2: Creation of a workgroup

Once the 1st step is clarified, the 2nd step concentrates on setting up a working group focussing on the described issue/problem. This working group should normally be established by an administrator who is in charge of managing a certain risk, either due to internally identified weaknesses of a given management system or stimulated from outside the organisation (e.g. by pressure of stakeholders). In any case, such a working group should combine all the available administrative competence and expertise with regard to the addressed risk.

This working group aims first of all at defining a procedural path that is in line with the characteristics of the addressed risk and the given legal and socio-cultural background. Here, some key-questions are: 
- What is the aim of the group/project? The problemframing should be clear.

- Who are the people/institutions who should be invited to participate in the working group? This depends on the topic: sometimes various experts in different fields are necessary. However, the people in charge of the specific risk issues have to be involved;

- How many people should be invited to participate in the working group? Too many participants may cause endless discussions that could delay or even elude a result.

These questions drive the overall process and determine the actions to follow. It is also possible to create several subgroups, which is recommended primarily in case of a complex risk setting and/or involvement of people with very different professional backgrounds. In this case, special attention should be paid to the coordination of the subgroups.

The process will certainly be more efficient and lead to more satisfying results if the public and/or private bodies that are legally responsible for decision-making are represented right from the beginning. A person or a small team should be appointed who will be in charge of the procedural aspects. Furthermore, an external facilitator should be considered to offer support and join the process. Such support contributes to money saving and efficiency (e.g. it ameliorates problems owing to different hierarchical levels or different understanding of certain topics) and offers professional help in dealing with emotional responses to risk.

Step 3: Agreement on Objectives (including indicators for measurement)

In the 3rd step, the working group has to agree on goals as a basis for the elaboration of risk mitigation measures. Here, one should take care that only realistic and attainable goals are selected. Otherwise the whole process can be doomed. The goals have to be defined as clearly and simply as possible. Only the appropriate selection of goals will lead to an appropriate and promising process!

\section{Sub-Step 3.1 Definition of appropriate indicators}

In connection to the defined goals/objectives, appropriate indicators should be selected also to measure the given objective (the guiding question for selecting indicators could be: how can the objective/goal be measured?). These will provide a structure for commonly agreed solutions to the given problem, allowing steady improvement and continuous monitoring. However, indicators alone cannot meet the demands of a risk-reduction objective; appropriate measuring values are needed.

\section{Sub-Step 3.2 Definition of appropriate measuring values}

A prerequisite for an assessment is the existence of clearly defined (qualitative and quantitative) measuring values for each of the defined indicators. The measuring values shall ideally be identified by the working group. They show the current performance of a certain indicator. Here, the guiding-question for every chosen indicator is: how can the indicator be measured?

Sub-Step 3.3 Classification of measuring values

Once the measuring values are elaborated, appropriate levels for their classification have to be chosen. The number of classes may vary between the indicators. There might be indicators that need only three classes to describe their performance, others might need five. The following example indicates a case of five classes. This classification allows the assessment of the performance of a given process (Website Balanced Scorecard):

- Red = initial (with no formal process);

- Orange $=$ managed (processes are planned and controlled);

- Yellow $=$ defined (processes described in standards, tools and methods);

- Green =quantitatively managed (sub-processes are controlled using data analysis);

- Blue = optimizing (data are used to continuously improve processes).

Step 4: Agreement on mitigation measures

In order to accomplish the given (theoretical) objective fixed in the 3rd step, it is necessary to define appropriate and feasible mitigation measures. This should be done by the whole group to guarantee the acceptance of the mitigation measures. It is obvious that every objective agreed on and defined in the process (see 3rd step) should be realised by corresponding mitigation measures. In this context some aspects should be taken into account:

- Who will be the responsible authority/authorities for the realization of the mitigation measure(s)?

- What is the most appropriate mitigation measure(s) to meet the objective?

- Where is/are the mitigation measure(s) to be located? (with a geographical localisation on a map)

- What are the approximate costs for the realisation of the mitigation measure(s)?

- What is the appropriate time and time horizon for the realisation of the mitigation measure(s)?

- How efficient is/are the mitigation measure(s)?

The indicators identified in the 3rd step should be used as measuring instruments. It is possible to assess and compare several mitigation measures by using these indicators and selecting the most appropriate ones according to their efficiency in meeting the overall objective. Table 2 shows an example from Italy for the case of forest fires. 
Table 2. Example of the context of objective, measures and indicators according to the Italian case study (Source: own elaboration).

\begin{tabular}{|c|c|c|c|}
\hline Example of an & \multicolumn{2}{|c|}{ Possible mitigation measures } & Indicator \\
\hline \multirow{4}{*}{$\begin{array}{l}\text { Reduction of forest fire } \\
\text { risk in the Lazio Region }\end{array}$} & \multirow{4}{*}{$\begin{array}{l}\text { Interaction between } \\
\text { Civil Protection and } \\
\text { Urban and Spatial } \\
\text { Planning }\end{array}$} & $\begin{array}{l}\text { Identification of vulnerable } \\
\text { areas by integrating data from }\end{array}$ & \multirow[t]{3}{*}{$\begin{array}{l}\text { Number of newly identified } \\
\text { vulnerable areas }\end{array}$} \\
\hline & & Civil Protection and Urban & \\
\hline & & Plans (Alternative 1) & \\
\hline & & $\begin{array}{l}\text { Increase awareness among pro- } \\
\text { fessional associations (e.g. of } \\
\text { architects, urban planners and } \\
\text { engineers) by means of a ques- } \\
\text { tionnaire (Alternative 2) }\end{array}$ & $\begin{array}{l}\text { Number of filled in } \\
\text { questionnaires }\end{array}$ \\
\hline
\end{tabular}

The chosen indicators and relevant classifications facilitate the assessment of the state-of-art as regards coping capacities in dealing with risk (see explanations in Sub-step 3.3). The results can be shown on a scorecard. A scorecard is a tool which shows if activities on a specific issue are in line with overall objectives.

Step 5: Testing of feasibility/applicability of measures agreed upon and designation of implementation processes (i.e. key agencies and actors, timetables, leadership, intermediate and final products)

This step refers to the move from decisions to real action. The procedure includes selection of key agencies or actors to implement measures, assignment of tasks to actors, addressing the obstacles to implementation arising from public administration inertia, resistance on the part of Civil Society, etc. This is a very crucial step because the results of the measure depend largely on the selection of the agencies and persons in charge, on the selection of a well-fit implementation process, on addressing barriers, and so on. It presupposes agencies and individual persons taking initiatives and pilot actions and having leadership qualifications, especially if the application of measures necessitates the activation of voluntary groups. It also presupposes a resilient philosophy of implementing measures by minimizing extra needed resources, taking advantage of opportunities, etc.

Step 6: Agreement on indicators and measuring values for the contributions of the participating partners concerning the achievements of objectives

In the 6th step the participating partners contribute to the elaboration and selection of appropriate indicators and measuring values for the mitigation measures which are performed by each actor. The guiding questions in this context are:

- How can the contribution of involved partners be measured?

- How can the effectiveness of the involved partners concerning the implementation of objectives be measured? (Effectiveness of contribution of partners involved).
The results of the "Agreement on Objectives" can be measured by means of effectiveness and efficiency indicators. The effectiveness indicators measure the extent to which a goal has been reached for a given field of action or mitigation measure. This allows a comparison between the planned and actually achieved outcome. Such indicators are the effect of a complex cause-and-effect chain that combines output with impacts and outcomes. On the contrary, the efficiency indicators give information about the planned and real development of a given output, because efficiency is derived from the comparison between the input and output of a mitigation measure. Here, the comparison between required values and the measured, achieved values can be carried out in several output-dimensions:

- quantitative;

- qualitative;

- cost objectives (cost recovery);

- satisfactory objectives (target-group oriented).

A real impact-control is not possible but also not necessary, because there are several driving factors which influence the status of a system, such as demography or economic change. A shrinking in GDP might lower the given damage potentially much more than a certain agreed measure (e.g. retrofitting of existing building structures). In case of monetarily quantifiable risks, the output could be expressed in terms of the evolution of annualized average losses compared with a fixed goal (success-control).

Step 7: Determination of appropriate stakeholders (target group) and information policy

The 7th step can be regarded as a basic step concerning not only trust-building but also acceptance of the mitigation measures in a given area. From the early beginning, appropriate stakeholders should be included in the whole concept-cycle. The responsible authorities should be aware that inadequate information about risks, inapprehensible procedural steps, as 
well as insufficient involvement of the public in the decisionmaking process lead to severe criticism and mistrust which undermines respect of relevant decisions (e.g. a given mitigation measure). Trust has a key role in dealing with risks: only those who are well informed and integrated in the process will accept the decisions made by the authorities.

The "Agreement on Objectives" or a treaty (as a possible result of the "Agreement on Objectives") necessitates also the involvement of corresponding (and indirectly concerned) stakeholders. Appropriate procedures of participation and information paths should be selected.The degree of involvement should be chosen in accordance with the level of the risk governance process (not every stage of the risk governance demands intensive involvement of stakeholders). The following guiding questions concerning the stakeholders can be used to measure the progress and level of the participation process:

- To what extent are stakeholders identified (through a proper process - incl. prioritisation)?

- To what extent are all relevant social groups and their expectations known?

- To what extent are all relevant social groups motivated/involved?

- To what extent is information accessible?

- To what extent are the stakeholders interested in having information, and in the outcome?

- To what extent do the stakeholders trust the decision makers, institutions and information available?

- To what extent do the stakeholders accept the process and the outcome?

- To what extent is the dialogue constructive (one that guarantees listening and mutual understanding)?

Step 8: Continuous monitoring/review of risk governance process and continuous consultation

It should be clearly stated that the objectives, selected indicators, measuring values, as well as indicator classifications are subject to a dynamic process and are neither static nor unchangeable. They have to be adapted periodically to the expectations and requirements of the responsible body or institution, as well as to the existing and possibly changing circumstances. Additionally, the changing activities of institutions and the progress of review cycles influence the measurement values and classifications. Therefore Step 8 runs in parallel to all other steps as indicated in Fig. 2 above.

\section{Bringing theory into practical implementation}

The following sub-chapters present a short description of the case studies elaborated during the INCA project, i.e. City of Dortmund (Germany), East Attica region (Greece), and Lazio Region (Italy). The sections highlight the implementation process of the agreement on objectives in these three territories with respect to the respective exposures to flash floods and forest fires. The agreed and applied mitigation measures are also included.

\subsection{The case of the city of Dortmund facing flash floods}

The city of Dortmund is located in the Ruhr-Area (as part of the Federal State North Rhine-Westphalia, Germany) (see Fig. 3). Its population of 583945 inhabitants (census 2007) and an area of about $280 \mathrm{~km}^{2}$ (with a population density of 1260 inhabitants per $\mathrm{km}^{2}$ ) make Dortmund the largest city in the region (Stadt Dortmund, 2007). The area of Dortmund is traversed by the Emscher River from the east to the northwest (see Fig. 3). About $40 \%$ of the catchment area consists of poldered ${ }^{1}$ surfaces. In Dortmund, large parts of the city's territory subsided up to $20 \mathrm{~m}$ as a result of former coal mining activities. Nowadays, these areas are equipped with artificial drainage facilities. The main watercourse of the Emscher River is largely surrounded by dikes, especially in areas with subsidence caused by mining.

The most meaningful event for the scope of the present paper has been a flash flood that occurred in July 2008. During only three hours the amount of precipitation reached the level of $200 \mathrm{~mm}$. This was more than double the average precipitation of July. The reason for this was a stationary thunder cell. The losses of about 17.2 mio. $€$ were caused due by an overstraining of the water-managementinfrastructures which failed to cope with the situation. This event highlighted the possibilities and especially the limitations of technical flood protection measures and of the management system at the local, regional, and river catchment area level (Grünewald, 2009). Especially in the case of flash floods that is represented by the Dortmund example, emergency response tends to be the weak stage of the risk management cycle due to the rapidly developing hazardous event. In such hazard cases, prevention and spatially-differentiated preparedness measures have a special importance. These in turn necessitate risk-sensitive spatial analysis and planning.

The discussion on the problem described before (Step 1) led to the definition of the basic overall objective, i.e. Mitigation of risk in case of flash floods in Dortmund. This was the starting point for the establishment of a main working group that tried to deal with the challenge. In order to become operational, this objective was further split into four sub-objectives (see Fig. 4).

The selection of sub-objectives was based on the experience of the participants of the working group (Step 2). The

\footnotetext{
1 A polder is a low-lying tract of land enclosed by embankments known as dikes and forming an artificial hydrological entity, meaning it has no connection with outside water other than through manually-operated devices.
} 


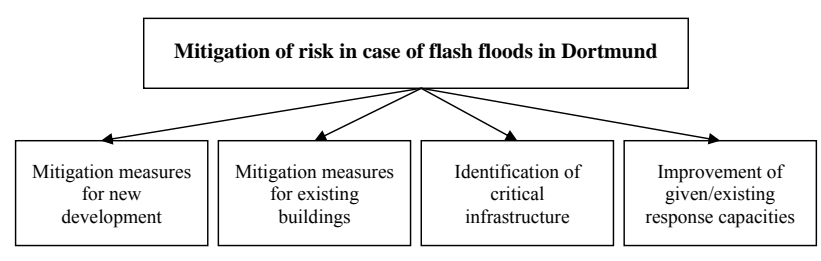

Fig. 4. Hierarchy of objectives (Source: own elaboration).

intention was to strengthen the mitigation pillar of the disaster cycle (especially evident in the first three sub-objectives), but also to improve the reaction time of the civil protection authorities.

Besides the issue of appropriateness of the stakeholders in relation to flash floods, other risk management questions were: who should be involved in the work, who should cooperate with whom, and who could take decisions within the scope of own responsibility. The main working group consisted of the following institutions/stakeholders:

- City office of Heavy Engineering, Sewage Division;

- Environmental Agency, Lower Water Authority;

- Urban Department of Planning and Building;

- Emschergenossenschaft (association for water management);

- Fire Department; Crisis Management Group;

- DEW (Dortmund Energy and Water); and

- TU Dortmund University (as mediator).

The work of this group was aimed at communicating the strategies that were elaborated in each of the participating institutions. It was obvious right from the beginning that decision-making and work should be structured into more detailed sub-objectives, so as to become operational (see before). Therefore, the working group decided to split into four sub-groups in line with the four sub-objectives mentioned above. As individual institutions did not have expertise and were not interested in the whole range of sub-fields involved, splitting objectives and working groups was considered as an efficient action to take in the implementation process.

The focus of attention of each working group was established after discussion of the different aspects and points of view (identification ofweaknesses and threats concerning the actual dealing with risks). As a consequence, the achieved results reflect a synthesis of the different perspectives which is also reflected in the indicators and measuring values.

The sub-group on new developments, for instance, agreed on a flood-proof of future, legally-binding land-use plans. This concerns several aspects:

- water bodies (e.g. is the legally-binding land-use plan located in a flooding area?);
- sewer system, (e.g. how will the rain water be discharged?);

- emergency water path, (e.g. how to direct flood water what exceeds the capacity of the sewage system?);

- streets and roads, (e.g. what "design" characterises the streets/roads)

- buildings and infrastucture, (e.g. is critical infrastructure envisaged in the legally-binding land-use plans?);

- communication, (e.g. are all appropriate stakeholders included?).

As most of the areas in Dortmund are already built and developed, the actions of the working group dealing with new development were limited. Nevertheless, the sub-group agreed that it is necessary that future, legally- binding landuse plans should be considered in terms of flooding (Step 4). This consideration refers to several aspects and related indicators:

- water bodies, (indicator: number of legally-binding land-use plans located in a flooding area?);

- sewer system, (for instance: how should rain water be discharged?);

- streets and roads, (indicator: what are the "design" standards of the streets/roads?);

- buildings and infrastructure, (indicator: is critical infrastructure envisaged in the legally-binding land-use plans?);

- communication, (indicator: extent of inclusion of appropriate stakeholders)

The key aspect and important for all four working groups was the identification of critical infrastructure located in the Dortmund area (related indicator: percentage of analysed territory of City of Dortmund). The term "critical infrastructure" describes organisations and facilities of strategic importance for the community, (i.e. telecommunications, power supply systems, banking/finance, transportation, water supply, emergency services). Their failure may lead to long-term supply bottlenecks, significant disruptions concerning public safety or other dramatic consequences (BMI, 2009).

As shown by Fig. 5 below, the identification of critical infrastructure was successfully done (Step 5). Mainly the historic city district centres such as Marten are at risk where no legally-binding land-use plans are in place which regulate land use and foster flood risk mitigation by designating water retention ponds and decentralised rainwater infiltration. Thus, an improved, regulative, land-use planning framework is required which aims at mitigating the given flood risk. Thereby, further building permissions should only be granted 


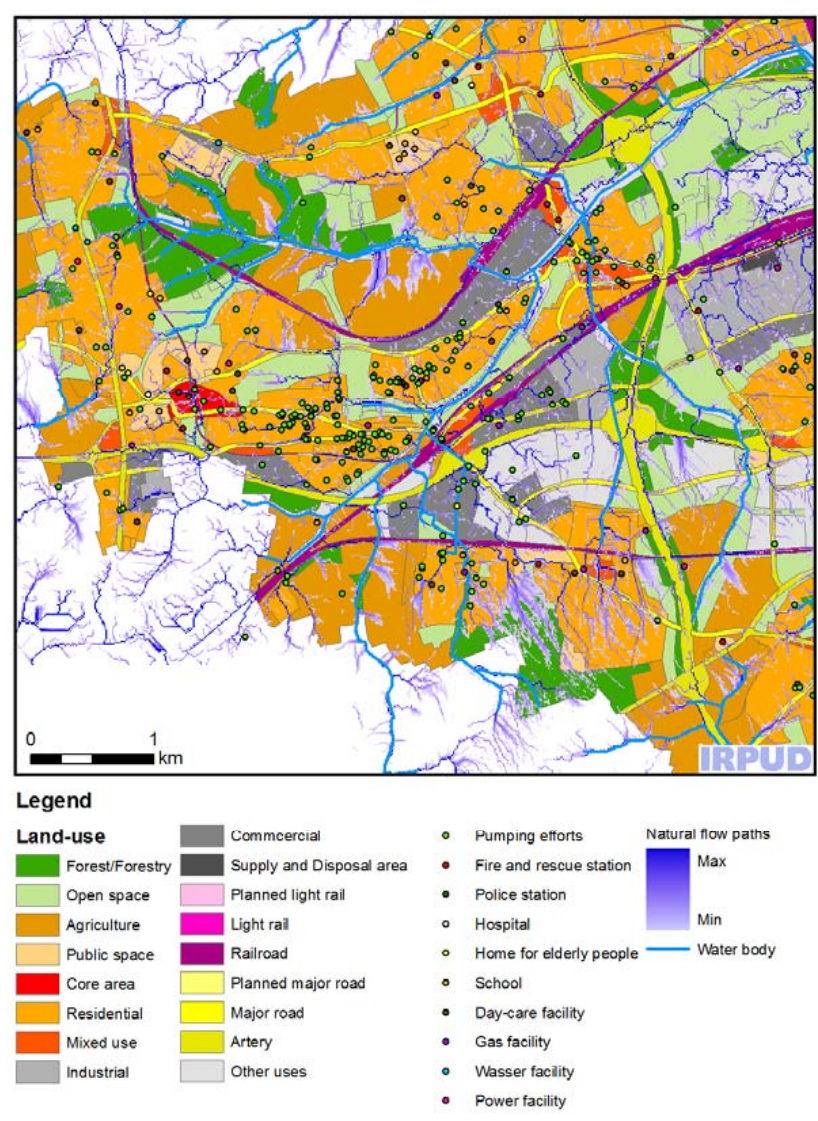

Fig. 5. Elements at risk. Source: own elaboration.

if there is sufficient discharge capacity. In addition, individual building protection could be required by concrete textual designations of legally binding, land-use plans. Moreover, this map served as evidence basis for the intended retrofitting of the power transformer stations which are at flood risk (operated by the local energy supplier DEW 21).

Furthermore, checklists with building precautions versus floods were elaborated. This was envisaged as a mean of raising the awareness of, e.g. the architects who influence building construction and design and the adoption of flood resistance standards.

As an additional measure, it was decided that inspections for the purpose of fire protection (obligatory in Germany) should include compliance with flood protection standards, too. The related indicator is: percentage of inspections in which the issues of flood protection are covered. The appropriate classification is done in three steps as shown in Table 3.

It was acknowledged that the responsibility of the building owner should not be neglected (self-precaution). Raising risk perception of building owners was considered achievable only in the long-term through such means as information campaigns, flyers, communication, etc.

The work within the group managing the aspect "improvement of existing response capacity" was seen as an important point because current response capacity was not considered satisfactory. Up to now, only basic equipment has been available and there is a need of special equipment to facilitate the action of the fire brigade and rescue services (e.g. powerful large pumps and transport to reach flooded areas). Another addressed problem concerned the call centre of the fire brigade. Waiting-time in case of emergency calls is too long, thus emergency calls get "lost" (the callers hang up). The problem of long waiting times before a rescue team arrives is also a challenge (the capacities are limited. Indicator: waiting time in minutes).

As most of the problems described are connected to the lack of financial resources, their resolution is not easy, at least in the short and medium terms. The working groups concentrated of course on those problems that could be resolved under given conditions of resource availability (financial, staff etc.). The mitigation measures proposed by the different sub-groups were an integrated part of the whole concept (see Step 6, i.e.). An agreement on indicators and measuring values for the contributions of the different participating partners (concerning the achievements of objectives) was a core element of the collaborative process. The related tasks, responsibilities, mitigation measures, and indicators were updated during the work within the case study according to new information (Step 8). Beside Step 8, also Step 7 was seen as an important aspect, as the results of the working groups were communicated in regular intervals.

\subsection{The case of the East Attica Region facing forest fires}

The Greek case study area occupies the eastern part of the Region of Attica where the agglomeration of Athens is located. The sub-region of concern was the area that falls under the jurisdiction of the Directorate of Forests of East Attica, the superior authority which exerts forest policy guidance and control over the Forest Service Offices (FSOs) of Kapandriti, Parnitha, Penteli, and Lavrio (see Fig. 6). The Directorate of Forests of East Attica lies within the wider structure of the administrative organization of the Attica Region.

The specific area of East Attica was selected as a case study because it represents an instructive example of mismanagement of forest fire risk potential in Greece. The selected sub-region is an area of $1930 \mathrm{~km}^{2}$, which approximates but does not coincide with the former Prefecture of East Attica $^{2}$ which in 2001 amounted to 403918 inhabitants (National Census of 2001).

According to Sapountzaki et al. (2011), East Attica receives the urban sprawl of the Athens agglomeration and is dotted with satellite settlements (especially along the eastern coastline) which are continuously growing. They are

\footnotetext{
${ }^{2}$ Prefectures have been abolished altogether as a result of the 2010 national reform of the local and regional governance system, known as the "Kallikratis" plan
} 
Table 3. Scorecard for indicator "percentage of inspections". Source: own elaboration.

Issues of flood protection are not covered during planned inspections

Discussion on the need for addressing issues of flood protection during planned inspections has started

Issues of flood protection are covered during planned inspections, continuous monitoring and verification is implemented

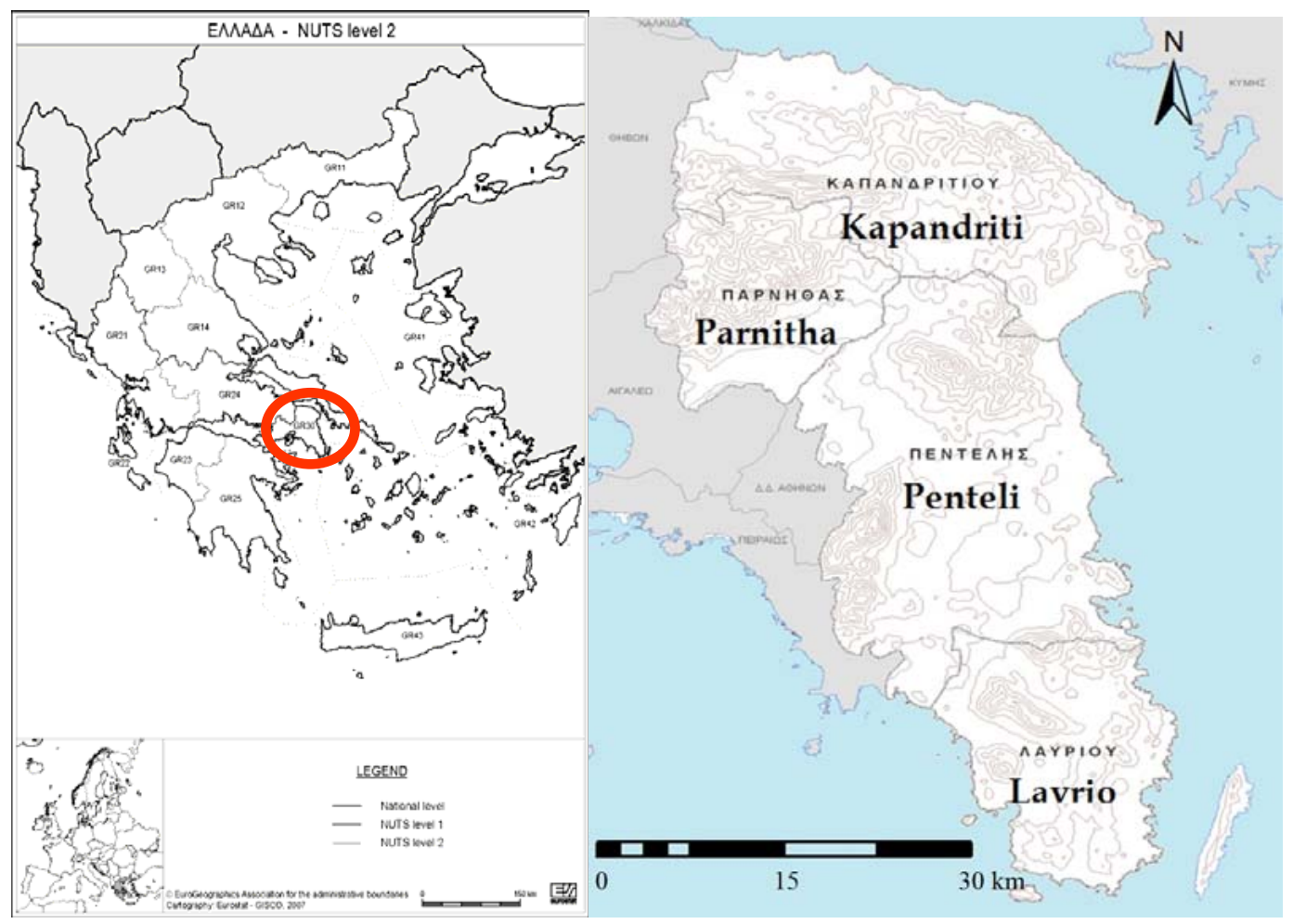

Fig. 6. Location of the Region of Attica in Greece (left; Source Eurostat, 2007) and the study area within (defined by the jurisdiction of the Directorate of Forests of East Attica) (right; Source: Region of Attica, 2009).

dominated by second homes or semi-permanent residential developments. Also, East Attica hosts the new international airport "Eleftherios Venizelos" which attracts speculative land uses and entrepreneurial activities yielding high land revenues and raising land values in the vicinity.

Above authors emphasize that due to ineffective fire investigation procedures, most of the fire events in the wider Region of Attica are registered as events of unknown causes. The respective percentage has increased from $41.7 \%$ by 1990 to $66.8 \%$ in the period 1991-2004 (Kaoukis, 2009). Official ignorance of the actual root causes of the catastrophic phenomenon is a precursor of an ineffective risk management system.

It is reliably suspected, however, that the phenomenon is connected with the high demand for building development land and the gradual transformation of East Attica into a mixed wild-land/urban/holiday-making area. This is supported by the factual observation that the "winners" of forest fires (in the long term and after successive catastrophic events) are predominantly (a) building development and (b) mixed patterns of land cover where forests or cultivations are intermingled with building clusters and technical infrastructure. Despite the above, widespread, empirical indications of the importance of spatial planning, it is clear that it remains totally absent from the forest fire risk management system (Sapountzaki et al., 2011).

Horizontal interactions between the three Directorates are almost non-existent. After the stimulus generated by the INCA project, a core Working Group has been established in the Region of Attica to serve the "Reduction of Forest Fire Risk" as an umbrella-objective. This consisted of members of the Region of Attica (REGAT), all three Directorates, the Harokopio University of Athens (HUA), and the National 
(Greek) Agricultural Research Foundation (NAGREF). In particular its members have been as follows:

- the head of the Directorate of Forests of East Attica (REGAT);

- the head and representative of the Office of Civil Protection of REGAT;

- representative of the Directorate of Environment and Spatial Planning of REGAT;

- representatives and members of the research teams of HUA and NAGREF.

After Step 1 and 2 above, the following paragraphs indicate how the "road map" was developed afterwards and present the step-by-step process in the specific case of East Attica region.

Step 3: After the establishment of the core Working Group, four meetings were organized and attended by the working group members. As mentioned above the basic issue of the agenda of the four meetings was the "Elimination of the Risk/Danger of Forest Fires in the Eastern Attica Region".

The 1st meeting arrived at a partial consensus regarding the specific goals to be pursued by the working group, all of them conducive to the basic, above objective of the reduction of forest fire risk:

- 1st objective: reduction of the number of forest fire events owing to negligence and ignorance causes (predisaster prevention phase);

- 2nd objective: early detection of fire ignition points (presuppression and preparedness phases);

- 3rd objective: intensification of the search/detection of the unknown causes of the phenomenon (prevention phase);

- 4th objective: enhancement of prevention and preparedness versus forest fires and boosting participation of the civil society in relevant processes as well as in reforestation (all phases of the disaster cycle including recoveryrehabilitation).

Especially the 4th objective, regarding involvement of the civil society in prevention, preparedness, and reforestation, was considered highly relevant and significant; however, this prioritization necessitated enlargement of the working group to include critical stakeholders with accessibility to the civil society. Indeed, it was decided during the 1 st meeting that the working group should enlarge to incorporate Local Authority representatives, volunteer firemen or representatives of NGOs. In essence this is about feedback from Step 3 to Step 2 so as to change the initial Working Group.
Steps 4 and 5: during the 2nd meeting, a special committee within the wider working group was constituted in order to accommodate the development of channels and processes of communication (regarding forest fire issues) among the Civil Society and Local and Regional Government. These channels were considered an essential precondition for the information, awareness, and involvement of the lay public in the management of forest fire risk. The decision-making process was based on the suggestions made by the research team - acting as mediator - and which pivoted on the results and agreements of previous meetings regarding goals and measures to be pursued.

Four measures were chosen for implementation by taking into account not only the objectives established but also some additional criteria such as social/political acceptance, administrative cost minimization, the limited time available, availability of human and other resources by Local Authorities willing to be involved, etc. These criteria to ensure the feasibility and applicability of the measures (see Step 5 in Fig. 3) implied a repeatedly-occurring feedback loop from Step 5 to 4 and again back to 5 .

It is worth mentioning that the agreed measures (not only as a group but even individually) facilitate coordination/communication and synergies between Forest Policy, Spatial Planning, and Civil Protection. In particular:

- Measure 1: awareness training of the Public on Forest Fire Causes and Management Issues (Training seminars addressed to pupils of 12-14 yr of age). This is a Civil Protection measure, contributing however to forest fire prevention by means of spatial planning through the emphasis given to the land-use conflicts behind the causes of the phenomenon;

- Measure 2: enhancing Self-defence of Residences Versus Fires (in forest-residential areas) and Creation of a Relevant Geo-data Basis (to support preventive spatial planning in mixed forest residential areas). This is a measure coupling Civil Protection and Spatial Planning;

- Measure 3: correction of Ambiguities, Contradictions, Uncertainties regarding (unspecified) Competences at the Regional and Local Level Affecting Forest Fire Risk and Possibilities of Risk Mitigation (relevant to spatial planning, civil protection and forest policy). This is a measure articulating Sectoral Planning with Spatial Planning and Civil Protection from the point of view of public administration competences;

- Measure 4: coordination between the Local Authorities and Forest Service as regards Forest Fuel Clearance Works. This measure links Sectoral Planning Authorities at different levels of the legal-administrative system (vertical coordination).

Measure 4 failed in implementation; the other three have been consistently implemented rendering impressive results. 


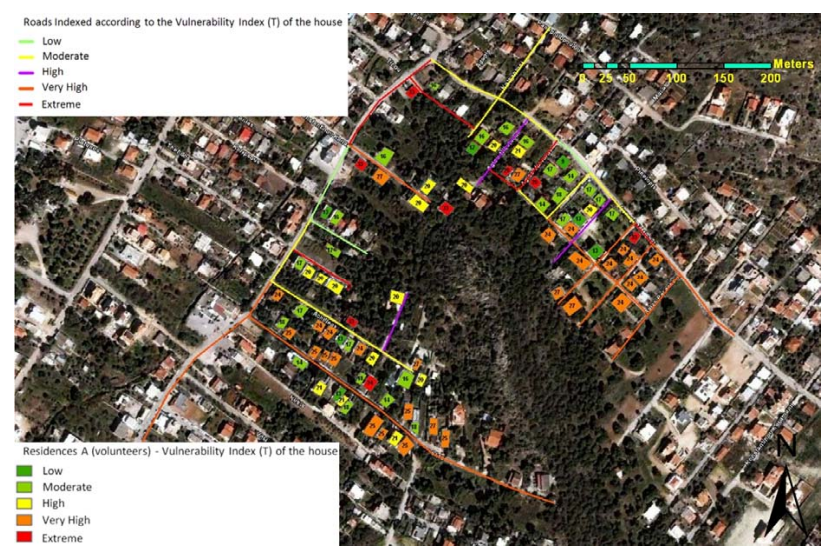

Fig. 7. Houses and roads are classified as to the level of vulnerability of residence (T) (Source: Xanthopoulos et al., 2010).

Steps 6 and 7: Implementation results and monitoring indicators are presented below only for the case of measure 2 as an indicative and representative example. Implementation of the 2nd measure necessitated first a field survey (in areas identified and delineated with the help of Google Earth) on the basis of a building registration card specifying criteria and conditions of building exposure and vulnerability to forest fires (see Fig. 7). It was decided that the survey should and could be carried out by the volunteering groups (for forest fires) of the Municipality.

Altogether 86 buildings were surveyed in relation to their vulnerability and risk of destruction features and conditions. Consequently, all registered buildings have been evaluated quantitatively (by the NAGREF research team) regarding their vulnerability and risk of destruction level and have been included in a relevant thematic map (covering a hill which is a mixed forest-residential area). As a final step, the NAGREF team sent the final scores of the surveyed buildings with reference to their weak points back to the owners to get their responses (via an additional questionnaire attached to the document with the scores). The analysis and assessment of the 86 building registration cards has been followed by the production of thematic maps illustrating the vulnerability index of streets and buildings (see Fig. 7), risk index in relation to the characteristics of fire, and a total risk index regarding the potential of the destruction of buildings. These maps constitute a valuable background for micro- and local scale spatial planning interventions to mitigate risk levels.

The basic achievement of this measure is the involvement of the Municipality and volunteer fire fighters in a form of Spatial Planning targeted to the purpose of risk management and familiarization of the public with the role and importance of Spatial Planning in forest fire prevention, (very important for the interconnected territorial governance processes).

Regarding input of the involved partners to the 2nd measure, this refers basically to (a) the volunteering groups recruited by Municipalities and accepting involvement in the field survey, (b) the Municipality technical departments keeping and updating a geo-data basis concerning the Out-ofPlan mixed forest residential areas and (c) the academic research staff specialized in forest fire issues and willing to offer advisory services relevant to exposure/vulnerability mitigation. The respective Monitoring Indicators and measuring values are indicated in Table 4.

As concerns output of the applied 2nd measure, the respective elements to be monitored are: (a) the number of filled registration cards (by volunteers surveyors), (b) the area of mixed forest-residential areas covered by thematic maps on fire risk and vulnerability levels of existing buildings within and (c) the population of contacted owners/tenants to be given information and advice regarding their vulnerable properties and risk mitigation necessities. The respective monitoring indicators and measuring values are also included in Table 4. Finally, the impact of the applied measure on targets and established objectives can be anticipated by indicators reflecting reduction of exposure and vulnerability levels at both scales of the individual building (micro) and wider territories (forest-residential).

\subsection{The case of Lazio Region facing forest fires}

The Italian case study was implemented considering the forest fire risk involving the south of the Lazio Region, and in particular the Province of Latina, which in the last years (between 2004 and 2009) suffered the highest proportion of forest fires in the region. An overview on the distribution of forest fires in the Lazio Region in 2010 is offered by Fig. 8 .

The main goal of the case study in the Lazio Region was "reduction of forest fire risk" by means of actions supporting institutional cooperation between Civil Protection and Urban Planning at regional level with an impact at local level (and therefore two offices which are in charge of different parts of the disaster management cycle presented in Fig. 1). Starting from the awareness of a lack of horizontal coordination between the responsible authorities in terms of risk prevention, in Step 1 of the application of the concept of agreement on objectives the Civil Protection Department of the Lazio Region (PCRL) underlined the need of a more intense collaboration with other departments of the region (as e.g. spatial planning) in order to mitigate the risk. Moreover, the case study highlighted the need of balancing improvements for a rapid and effective suppression mechanism on the one hand and the need for an appropriate pre-disaster preventive spatial planning on the other. The importance of building a broad consensus obtained by means of a participatory approach and negotiation of the demands for building and new development plans was acknowledged.

As Step 2, the working group was set-up involving the Lazio Region Department of Civil Protection, the Lazio Region Department of Territorial Planning, the National Research Council - Institute of Research on Population and Social Policies (Consiglio Nazionale delle Ricerche - Istituto 
Table 4. Monitoring indicators for Measure 2 (Creation of a geo-data basis for the mixed, forest- residential, Out of - Plan areas of East Attica) (Source: Sapountzaki et al., 2011).

\begin{tabular}{lll}
\hline The steps/to be controlled & The element to be monitored & $\begin{array}{l}\text { Monitoring Indicators (and Measuring } \\
\text { values) }\end{array}$ \\
\hline
\end{tabular}

\begin{tabular}{|c|c|c|}
\hline \multirow{4}{*}{$\begin{array}{l}\text { The input of the involved part- } \\
\text { ners (the Region of East At- } \\
\text { tica, the respective Municipali- } \\
\text { ties, the Research Institutions) }\end{array}$} & \multirow{2}{*}{$\begin{array}{l}\text { The volunteers fire-fighters of } \\
\text { the Municipality/Region em- } \\
\text { ployed in the survey }\end{array}$} & $\begin{array}{l}\text { Proportion of the population of volun- } \\
\text { teers participating in the building sur- } \\
\text { vey }\end{array}$ \\
\hline & & $\begin{array}{l}\text { Man-hours of volunteers dedicated to } \\
\text { the building survey in mixed forest- } \\
\text { residential areas (on a yearly basis) }\end{array}$ \\
\hline & $\begin{array}{l}\text { The data basis of the Municipal- } \\
\text { ity/Region regarding Out-of Plan, } \\
\text { forest-residential areas }\end{array}$ & $\begin{array}{l}\text { Availability (per Municipality) of a geo- } \\
\text { data basis (YES/NO) and of specialized } \\
\text { personnel to manage its constant updat- } \\
\text { ing (YES/NO) }\end{array}$ \\
\hline & $\begin{array}{l}\text { Academic- Research staff specialized } \\
\text { on forest fire issues and available for } \\
\text { consultative/ advisory services }\end{array}$ & $\begin{array}{l}\text { Man-hours of researchers /consultants } \\
\text { devoted to vulnerability estimation, sta- } \\
\text { tistical analyses and advice on mitiga- } \\
\text { tion actions }\end{array}$ \\
\hline \multirow{4}{*}{$\begin{array}{l}\text { The effectiveness and efficiency } \\
\text { of the survey, assessment and } \\
\text { mapping of Out-of-Plan build- } \\
\text { ings with regard to their vulner- } \\
\text { ability and risk of destruction } \\
\text { levels versus forest fires }\end{array}$} & \multirow{2}{*}{$\begin{array}{l}\text { The filled in questionnaires/forms } \\
\text { regarding building vulnerability } \\
\text { and fire risk level }\end{array}$} & $\begin{array}{l}\text { Numbers of filled in questionnaires per } \\
\text { time unit }\end{array}$ \\
\hline & & $\begin{array}{l}\text { Numbers of filled in questionnaires per } \\
\text { man-hour of volunteers }\end{array}$ \\
\hline & $\begin{array}{l}\text { The thematic maps on fire risk and } \\
\text { vulnerability levels of mixed forest- } \\
\text { residential areas }\end{array}$ & $\begin{array}{l}\text { Area covered by thematic, maps on } \\
\text { buildings' vulnerability and risk level } \\
\text { per year and per Municipality }\end{array}$ \\
\hline & The informed owners/tenants & $\begin{array}{l}\text { Numbers of informed building own- } \\
\text { ers/tenants per year and per Municipal- } \\
\text { ity }\end{array}$ \\
\hline $\begin{array}{l}\text { The impact of the building survey and } \\
\text { Vulnerability/Risk Mapping on the pos- } \\
\text { sibility of reducing forest fire risk in the } \\
\text { Region of East Attica }\end{array}$ & $\begin{array}{l}\text { Exposure and vulnerability condi- } \\
\text { tions/levels of the mapped mixed } \\
\text { forest-residential areas }\end{array}$ & $\begin{array}{l}\text { Degree of reduction of exposure and } \\
\text { vulnerability levels of buildings in the } \\
\text { mapped mixed areas per biennium per } \\
\text { Municipality }\end{array}$ \\
\hline
\end{tabular}

di Ricerche sulla Popolazione e le Politiche Sociali), the National Association of Italian Municipalities - Lazio (Associazione Nazionale dei Comuni Italiani - Lazio) and T6 Ecosystems Srl. The INCA working group defined the reduction of forest fire risk through an institutional cooperation between Civil Protection and Urban Planning on regional level with an impact on local level as objective for the process (Step 3), as there is a lack of horizontal coordination between the responsible authorities in terms of risk prevention, which means fragmentation, among others, between civil protection and spatial planning.

During a number of meetings, the following mitigation measures were identified in order to reach the previously defined objective (Step 4):

- identification of vulnerable areas by integrating data from Civil Protection and Urban Plans (it was implemented in the Municipalities of Sermoneta and Fondi);
- increase of the forest-fire risk awareness among professional associations (e.g. of architects, urban planners and engineers) by a questionnaire;

- revision and improvement of regional law L.R. 22 December 1999 , n. 38 on territorial government (Norme sul governo del territorio);

- guidelines for local administrations on the coordination of civil protection and territorial plans in order to identify and preserve vulnerable areas prone to forest fires (usable beyond the case study);

- planning and implementation of training for technical staff of public administration on coordinated planning methodology.

Activities for the implementation of the measures as a test of feasibility (Step 5) were focused only on the 1st and 2nd 


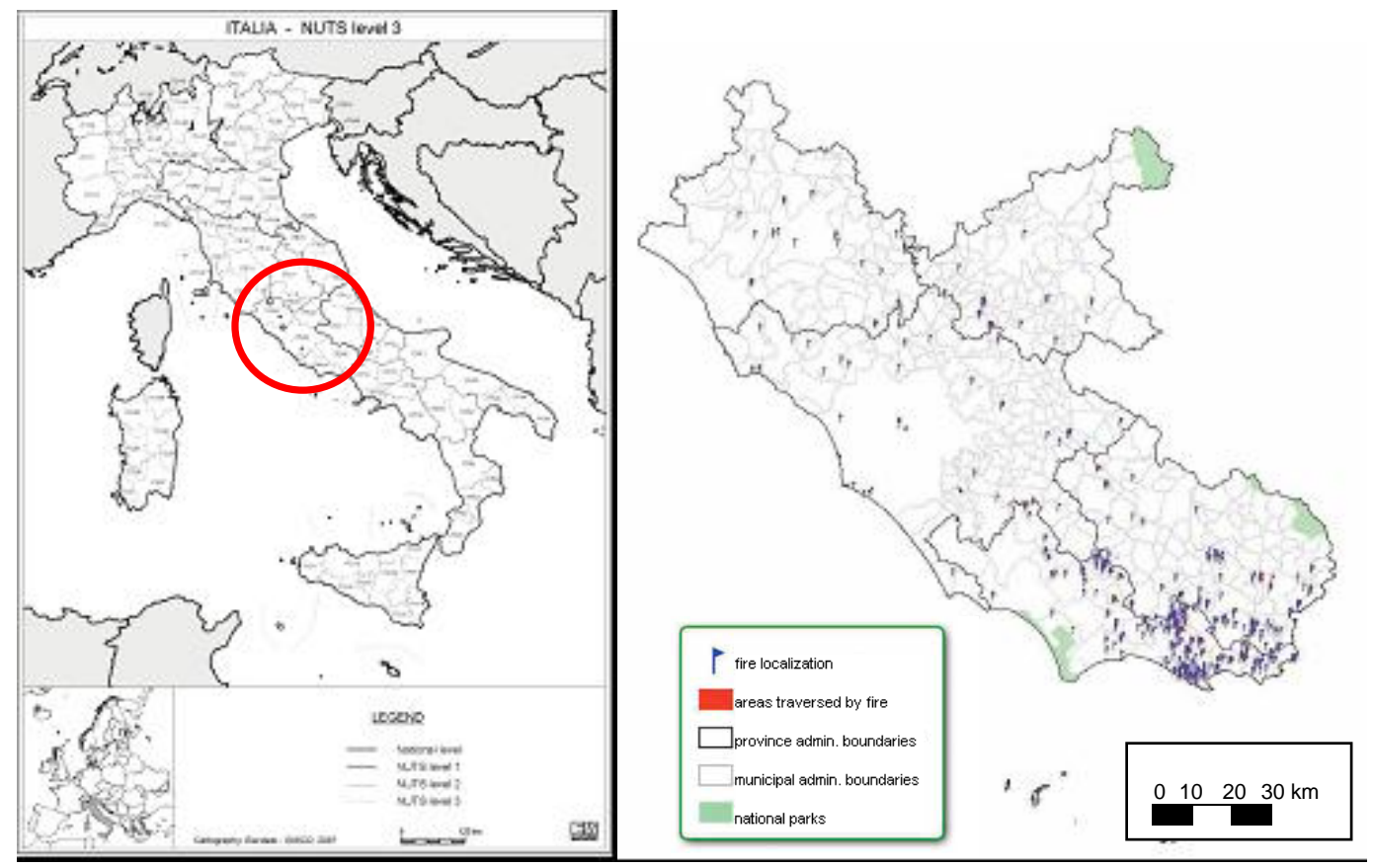

Fig. 8. Location of the Lazio Region in Italy (left; Source Eurostat, 2007) and Forest fires in the Lazio Region in 2010 (right; Source: Corpo Forestale dello Stato, 2010).

measure during the INCA project activities and the 3rd was discussed and prepared. The 4th and the 5th measures, however relevant, require special and continuous support to be implemented. In consequence, activities for Measures 1 to 3 are presented in the following.

Measure 1: Identification of vulnerable areas by integrating data from Civil Protection and Urban Plans

The aim of the 1st measure "Identification of vulnerable areas by integrating data from Civil Protection and Urban Plans" was to analyse the interface fire risk maps of the civil protection and intersect them with the territorial, urban, and landscape plan in order to identify critical structures and buildings that could be hit by such a phenomena to assign them a higher alert level. The related indicator was "Number of newly identified vulnerable areas" (see Table 2).

The experts in Civil Protection and in the Urban and Spatial Planning Department selected a range of maps and information that could be crossed and analysed to give new perspectives to the analysis of fire risk and fire exposure (e.g. the CTR (Regional Technical Map), PTPR (Piano Territoriale Paesistico Regionale), the Spatial Plan of Lazio Region, aerial photos; road system; vegetation and geology map; public and strategic services exposed to fire risk, etc.). The result was the identification of areas vulnerable to forest fires.

Measure 2: Increase awareness among professional associations

The formed working group decided that awareness of forest fire risk among professionals (e.g. architects, urban planners, construction engineers) is an important factor for prevention, as they are directly involved in planning processes and constructions, implementing technical work for municipalities. It was assumed that higher awareness would lead to an integration of forest fire risks in plans from the very beginning. A questionnaire was developed and distributed among the professional associations of the field in the province of Latina in order to achieve information on the three main critical aspects which emerged in the working group: development, control of the territory, and fire risk prevention. The related indicator was "Number of Number of filled-in questionnaires" (see Table 2).

One result was the lack of information on the analysed subjects even when they represent, as it is for Fire Registry, binding elements to territorial alterations. Other outcomes were that the Civil Protection Plan should be a local planning instrument covering various risks and showing models of intervention as well as legally-binding constraints, confirming the need of intersecting decision making process involving different competencies concurring in defining the different plans and decision-making tools for risk governance.

Measure 3: Revision and improvement of regional law L.R. 22 December 1999, n. 38 on territorial government

The Law of the Lazio Region "LR 38/99" regulates territorial government. It is aimed at the protection, arrangement, transformation and use of a territory and its attaining buildings. The working group decided to propose to the regional government an adaptation of Art. 37 of the Regional Law 38/99 with the aim to add a study on forest fire risk for setting-up new territorial plans in order to mitigate forest 
fire risk. This process continues after the end of the INCA project.

After the definition of the measures and some first results of their implementation, the working group agreed on indicators and measuring values for each measure and attributed an evaluation for the situation at the end of the case study (Step 6). As an example, the indicator and measuring values for Measure 1 (Identification of vulnerable areas by integrating data from Civil Protection and Urban Plans) are:

Indicator: Number of local analysis on vulnerable areas by integrating civil protection and territorial plans

\section{Classification:}

- Red - No local analysis implemented.

- Orange - Local analysis implemented in a case study area.

- Yellow - 50\% of local communities in the Lazio Region analysed.

- Green $-75 \%$ of local communities in the Lazio Region analysed.

- Blue - All local communities in the Lazio Region analysed.

Current state of the art:

- Orange - Local analysis implemented in a case study area

Stakeholder involvement and information (Step 7) is of major importance in order to guarantee acceptance of the measures taken in Step 4 and their implementation in Step 5. As resources were limited, the working group decided only on two activities which are, however, of high importance for the integration of the results and the dissemination of the measures:

- The municipality of Sermoneta was actively involved in the first measure and contributed comprehensively to its successful implementation. Various meetings were organised with the mayor and the technical representative for planning and civil protection. In addition, professionals who are in charge of territorial plans as well as volunteers (civil protection) were involved in the discussions and presentations. In order to give the work of Sermoneta some visibility, an excursion was made in the framework of the INCA final conference;

- A report was produced in Italian, focusing on the integration of civil protection and territorial plans for the identification of vulnerable areas and infrastructure. This report serves two targets: it is the basis for the suggestion of the adaptation of the regional law (measure 3), describing the background for such a suggestion. On the other hand it was distributed to all municipalities in the Lazio Region, providing strong arguments for its transfer.
It is important to mention that measures, indicators, and measuring values usually change over time with changes in the political, social, and economical context. This implies the need of continuous monitoring and review of risk governance process as well as continuous consultation (Step 8).

Support for continuous monitoring is provided by a software tool that has been developed within the INCA project. In fact, an output control software tool for monitoring and controlling the implementation process was set-up; it allows the definition of structural and non-structural mitigation measures, the possible outcome, suitable monitoring indicators, and criteria for the quality of chosen measures in order to ensure an output-control.

\section{Discussion}

The newly perceived, designed, and implemented concept of risk mitigation is intended to constitute a significant advance in the field of risk management, especially in prevention, satisfying at the same time the principles of risk governance.

As described before, the proposed method has been applied in two hazard cases and three territorial/administrative contexts: (a) the city of Dortmund facing flash floods, (b) the East Attica region facing forest fires and (c) the Lazio Region also facing forest fires. It is obvious that these three empirical processes, the respective achieved results, the obstacles encountered, and successes and failures experienced constitute valuable information for a documented review of the model and its wider validity. Evaluation however, necessitates points of departure or of reference in relation to which it would be possible to address progress or regression owing to the new model. Furthermore, evaluation necessitates criteria on the basis of which progress could be addressed.

Regarding the point or state of reference, the current situation (with the rigid, separate policies, plans and programmes of civil protection, sectoral risk mitigation, and spatial planning) constitutes the starting point. Regarding criteria of evaluation, the anticipated virtues and pursued advantages constitute the means of criticism and review. Further criteria for evaluation are: (a) the administrative cost entailed, (b) the motivational effect of the model on households and economic actors to take self-protection measures and to avoid riskincreasing ventures and (c) the political and social acceptability of the model (regarding liberty, fairness, environmental justice, etc). It is obvious that the efficiency and effectiveness of the model in relation to the ultimate objective of risk reduction can be evaluated only in the long run. Currently, effectiveness and efficiency should be judged with respect to intermediate sub-objectives only, i.e. successful pilot implementation of the agreed measures by the working groups. Whether this pilot implementation will constitute a leading example, whether it will be repeated in the future and become an embedded administrative routine procedure at the 
regional and local level and whether this process will lead up to radical risk mitigation is a matter of future studies.

In the following paragraphs, the method is judged in connection to a few results selected from the above criteria, in the light of the three case studies.

\subsection{The criterion of continuity in the Response - Preparedness - Prevention - Remediation (RPPR) chain}

Interconnection of measures targeting the different phases of the disaster cycle has been achieved in all three implementation cases. The envisaged continuity between the successive stages of risk management has been achieved in various ways:

- by knowledgeable working groups addressing the whole spectrum of management stages in the commonly agreed sub-objectives and measures and by assigning their implementation to their best collaborating members;

- by working groups providing for the mutual support and synergies among the above, commonly accepted subobjectives and measures;

- by working groups inventing measures which are inherently integral (in terms of the various management stages), meaning that they address and secure on their own coherence between the successive management stages;

- by working groups engaging in prevention matters, civil protection bodies, and agencies which traditionally are assigned only roles which are relevant to emergency response.

By its constitution, the working group, as long as it includes representatives of the various management stages and domains, brings the traditionally separate domains of relevant policy-making closer. To the extent that the working groups can promote itself as a new political/administrative unit gaining always more power of policy-making, the situation regarding sequential association of management stages will always improve.

\subsection{The criterion of bridging gaps and correcting inconsistencies between civil protection, spatial planning and sectoral measures in risk management}

These gaps and inconsistencies in risk management may result in serious management problems. An indicative example is fire suppression operations organized without knowledge of existing water sources such as water tanks, which are possibly located in a territory at risk.

Such problems can be tackled in a number of ways:
- by inserting appropriate spatial information into civil protection and preparedness planning and reversely by updating and enriching spatial planning with civil protection information;

- by including risk mitigation goals in the agenda of spatial planning objectives;

- by familiarizing spatial planning authorities with risk, vulnerability, exposure, and risk mitigation issues and reversely by convincing the masterminds of emergency planning about the importance of spatial dimensions for the success of emergency and risk management in general.

The proposed approach has indeed the potential to employ a large variety of ways to coordinate several policy fields that are co-responsible in risk management. At first co-existence of spatial planners, civil protection experts and risk managers in the same working group facilitates an exchange of information among the differently-oriented participants and learning from each other in a sustainable way. The learning effect influences further work and leads to a new culture of collaboration. Secondly, the commitment of all participants to contribute to the implementation of co-decided measures implies that the commonly agreed measures have in most cases a multidisciplinary dimension necessitating input from all involved fields. An indicative example is the case of the measure of "Training seminars on forest fire issues addressed to pupils" adopted by the Greek working group. These seminars were structured in two sessions where the first covered the spatial planning dimensions of the catastrophic phenomenon while the second focused on the foresters' and forest fire managers' point of view.

Obviously this interweaving of spatial planning with civil protection and risk prevention that enhances the instruments available by risk mitigation, the spatial data base ,and thematic maps on "spatial distribution of flood-controlling infrastructure in relation to flood exposed areas", is one good example of such innovative tools. Another example is thematic maps on the "risk of destruction" and "vulnerability level of buildings" in mixed forest-residential territories and other map cases depicting "exposure-scapes".

\subsection{The criterion of coupling structural and non-structural measures to achieve risk mitigation}

It is widely acknowledged that risk mitigation suffers from unilateral reliance of the responsible administrations on structural or engineering hazard modification measures.

The proposed model is indeed an ideal method for the formulation of risk management solutions representing mixtures of measures which balance the engineers', social scientists', physical geographers' and managers' points of view. Most part of the added value out of the implementation of 
the concept in the three European regions is related to planning and realization of non-structural measures which might function as an adhesive tissue, binding together engineering infrastructure work with preparedness measures, etc. Eloquent examples of such integrated measures taken from the three Case Studies are:

- the creation of a spatial data base and thematic maps on risk and vulnerability levels of buildings in a mixed forest-residential area of the East Attica region. The maps address in combination the flammability of building construction materials, distance of forest fuels from the buildings, and accessibility standards of the emergency road network. These maps constitute guiding information platforms for comprehensive, mixed mitigation actions and interventions;

- the creation of a thematic map of Dortmund presenting pumping locations from past flood events in relation to locations of flood control critical facilities. These maps are again information platforms for the enforcement of packages of structural, training, and organizational measures of either public or private initiative;

- the creation of a map identifying the vulnerable areas (prone to forest fire) by integrating data from civil protection and urban plans, in the case of the Lazio Region. This is an important planning tool for the municipalities to guide future development activities and it is envisaged as a tool for adaptation/review of the regional law on territorial government;

The model offers the opportunity of balanced risk mitigation, meaning the employment of both structural and nonstructural measures. The only but crucial pre-condition is equal and active representation in the working group of those responsible for non-structural measures.

\subsection{The criterion of effectiveness and efficiency of the model and its sustainability}

Effectiveness refers to the realization of the consensually decided objectives (by the working group): how fast are these attained and with how much certainty? Besides, will it be possible for the approach to adapt to changing situations? Efficiency on the other hand is about the achievements compared to the input used, (i.e. economic costs but also social, political, psychological, environmental, etc).

The basic advantage of the model with respect to effectiveness is that it is an output-oriented process. This means that it is a management process designed to fit to the risk problem as it is manifested in the specific territory under consideration. This situation is very different from the conventional model where the risk management process is adjusted to the legal-administrative system which puts it into practice (input oriented model). The model's option is indeed revolutionary and opens wide horizons regarding the future mode of operation of public administrations, not only in the field of risk management but also in other policy fields.

At first glance, this adaptation of the responsible structure administering a risk problem to the problem's features and to optimal, mixed-policy solutions looks like a guarantee of effectiveness. However, obstacles may arise this time from the legal-administrative system, which may resist change in decision-making hierarchies, deny loss of political/administrative power, attempt to cancel any unfamiliar process and reject intruding external agencies. This is exactly what happened in the Greek and Italian implementation cases at the regional (in Greece) and provincial level (in Italy), respectively. The authorities were unwilling to participate in working groups initiated by an external initiative, i.e. coming from non-formal administrative actors and procedures. Thus, the implementation took place at the municipal level which is more open and flexible in administrative norms and procedures. However, it is obvious that the effectiveness of the model may be in jeopardy owing to the resistance to change (of the existing balance of power) on the part of the established political/administrative interests.

Nevertheless, the model provides for feedback that can occur at any step of the road map procedure so as to increase its chances of effectiveness. That is exactly how the working group synthesis and spatial range of objectives and measures can change in case frictions emerge among participants of the initial working group or if authorities (at the regional level) show unwillingness to participate. In any case and even if feedback provides an outlet, it entails considerable delays in the process of implementation reducing the effectiveness of the whole venture.

Regarding efficiency: it is guaranteed but only when the whole implementation process proves to be effective, i.e. all steps are implemented. Efficiency is facilitated by the participation of all involved authorities and stakeholders in decision-making (on mitigation measures and their application too), which entails aggregation of the whole range of available resources (public and private) and their employment for the common purpose. Under such circumstances, opportunities arise to use these resources with a common spirit of resource-saving by means of economies of scale, creation of synergies, etc. Hence, efficiency of the concept of agreement on objectives can be very high but depends on its effectiveness.

Finally, sustainability of the process within or alongside existing regional or municipal administrative procedures is indeed a tricky question. If the new model will not be embedded in the formal system, then the traditional pattern of policy-making will run in parallel and most probably will come in conflict with it. However, embedding the concept of agreement on objectives in the existing system presupposes political acceptance, restructuring of the administration pyramids, and radical changes in the culture of the public officials. It is evident that these changes are difficult and 
slow processes; besides such changes presuppose convincing, almost impressive results from pilot voluntary implementations of the concept of agreement on objectives. Only then imitators will appear and act as propagators and disseminators of the new process.

\section{Conclusions}

The concept of agreement on objectives is potentially able to lower the given disaster risk by bringing the actors involved throughout the disaster cycle together and improving the inter-organisational coordination. Moreover, the agreement on common objectives aims at a reduction of risk by a choice of effective, efficient and flexible measures whose impact is monitored through a continuous process.

This implies a shift from a top-down to a more collaborative form of decision-making, which means a shift from functional rationality to communicative rationality (De Roo, 2003). In this context, it is obvious that the focus on the problem itself shifts to its definition and the degree of consensus on that definition. Thus, decision-making is also about whom to involve in the decision-making process. Here, communicative rationality has to be seen as an essential part of decision-making. The concept of agreement on common objectives and the related road map have to be understood as a practical exercise in communicative rationality.

However, a problem of communicative rationality is related to the probably questionable or limited tolerance of the wider political context, i.e. the political-administrative system. Regions and other sub-national administrative entities in different countries enjoy different levels of independence in making their own risk mitigation policies. Therefore, sometimes lack of coordination at the regional level is basically explained by the dependence of sectoral policies at this level on decision-making at higher levels (national and even supra-national), i.e. the top-down model of policymaking. Therefore the proposed alternative strategy has to be flexible so as to be applicable at different spatial levels (in each case in conformity with the legal-administrative context of the specific member state). In cases of centralized political-administrative systems where the pattern of topdown policy-making and implementation predominates, the lower regional and local levels are bound by the upper ones to implement the policies of the latter and enjoy limited discretion to formulate their own and follow own paths to spatial planning and risk mitigation.

The presented road map has been considered as useful for overcoming the above obstacles and facilitating the process of "Agreement on Objectives". Nonetheless, the most important prerequisite for its applicability remains the willingness of the involved actors to reach an agreement on common objectives and actions to achieve them. However, the three test cases have underlined that such willingness exists even in different legal-administrative and cultural environments and must not be a contradiction to the genuine interests of organisations. Moreover, it was demonstrated that outputoriented management approaches that have been widely used for decades, i.e. in new public management, can be transferred to the management of natural hazards.

Edited by: T. Glade

Reviewed by: P. Schmidt-Thomé and two other anonymous referees

\section{References}

Armaş, J. and Avram, E.: Perception of flood risk in Danube Delta, Romania, Nat. Hazards, 50, 269-287, 2009.

Audit Commission: Management Paper On Target: the practice of performance indicators, London, 2000.

Blake, B., Thompson, B., Polk, W., Johnson, J., Duckworth, B., and Bevers, S.: S.W.O.T. Analysis - Identifying Your Strenghts, Weaknesses, Opportunities, and Threats, Texas, available at: http://ttap.tamu.edu/Curriculum/F.20SWOT20Anlaysis.pdf (last access: 22 February 2010), 2005.

Bundesministerium des Innern (BMI): Nationale Strategie zum Schutz Kritischer Infrastrukturen (KRITIS-Strategie), available at: http://www.bmi.bund.de/cae/servlet/contentblob/544770/ publicationFile/27031/kritis.pdf (last access: 15 July 2011), 2009.

Cools, M., Fürst, D., and Gnest, H.: Parametrische Steuerung - Operationalisierte Zielvorgaben als neuer Steuerungsmodus in der Raumplanung, Frankfurt a.M., 2003.

De Roo, G.: Environmental planning in the Netherlands - To good to be true: from command and control planning to shared governance, Hampshire, 2003.

European Commission: Communication from the Commission to the Council, the European Parliament, the European Economic and Social Committee and the Committee of the Regions - Thematic Strategy for Soil Protection Com (2006) 231 final, 2006.

European Commission: Territorial Agenda of the European Union, Brussels, 2007.

European Communities: Directive 2007/60/EC of the European Parliament and of the Council of 23 October 2007 on the assessment and management of flood risks, Brussels, 2007.

European Communities: A Community approach on the prevention of natural and man-made disasters, Brussels, 23 Feb 2009, $\operatorname{COM}(2009) 82$ final, 2009.

Eurostat: Regions in the European Union - Nomenclature of territorial units for statistics, NUTS 2006 /EU-27, available at: http://epp.eurostat.ec.europa.eu/cache/ITY_OFFPUB/ KS-RA-07-020/EN/KS-RA-07-020-EN.PDF (last access: 18 June 2011), 2007.

Fischhoff, B., Slovic, P., Lichtenstein, S., Read, S., and Combs, B.: How safe is safe enough? A psychometric study of attitudes towards technological risks and benefits, Policy Sci., 8, 127-152, 1978.

Greiving, S.: Report on Goverscience seminar on inclusive risk governance, Brussels, 2009a.

Greiving, S.: Zielvereinbarungen - ein neuer Ansatz zum Management von Hochwasserrisiken; Paper linked to the BMBF research project: Changes and management of risks of extreme flood events in large river basins - the example of the Elbe 
River, project website available at: http://www.veris-elbe.ioer. $\mathrm{de} /, 2009 \mathrm{~b}$.

Greiving, S., Fleischhauer, M., and Wanczura, S.: Management of Natural Hazards in Europe: The Role of Spatial Planning in Selected EU Member States, J. Environ. Plann. Man., 49, 739-757, 2006.

Grünewald, U.: Gutachten zur Entstehung und Verlauf des extremen Niederschlag-Abfluss-Ereignisses am 26.07.2008 im Stadtgebiet von Dortmund - einschließlich der Untersuchung der Funktionsfähigkeit von wasserwirtschaftlichen Anlagen und Einrichtungen der Stadt, Emschergenossenschaft und Dritter in den Gebieten Dortmund-Marten, -Dorstfeld und -Schönau, Gutachten im Auftrag der Stadt Dortmund und der Emschergenossenschaft, 2009.

Haering, B., Gsponer, G., and Koch, P.: Effor2 Konzeptbericht Wirkungsorientierte Subventionspolitik im Rahmen des Waldgesetzes; Umweltmaterialien Nr. 145, Bundesamt für Umwelt, Wald und Landschaft, Zurich, 2002.

IRGC: International Risk Governance Council, White paper on risk governance: Towards an integrative approach, Geneva, 2005.

IRGC: International Risk Governance Council: Risk Governance Deficits - An analysis and illustration of the most common deficits in risk governance, Geneva, 2009.

Johnson, D. B.: Public Choice - An introduction to the new political economy, California, 1991.

Kaoukis, C.: Forest Fires in Greece, period 1991-2004: Lessons from the evolution of the phenomenon, MSc thesis, Harokopion University of Athens, Greece, 2009 (in Greek).

Knill, C. and Lenschow, A.: On deficient implementation and deficient theories: the need for an institutional perspective in implementation research, in: Implementing EU environmental policy, New directions and old problems, edited by: Knill, C. and Lenschow, A., Manchester/New York, 2000, 9-35, 2000.

Krems, B.: Online-Verwaltungslexikon olev.de - Definitionen und Kurzerläuterungen; available at: www.olev.de (last access: 11 November 2010), 2007.

Lane, J. E.: New Public Management, Routledge, London, 2000.

Löfstedt, R.: Risk management in post-trust societies, Houndmills, Basingstoke, Hampshire, New York, 2005.

Meadowcroft, J.: Politics and scale: some implications for environmental governance, Landscape Urban Plan., 61, 169-179, 2002.

Neary, P. J.: Of hype and hyperbolas: Introducing the New Economic Geography, J. Econ. Lit., 39, 536-561, 2001.

Osborne, D. and Gaebler, T. A.: Reinvesting Government - How the entrepreneurial spirit is transforming the public sector, Reading, 1992.

Paddison, R.: City Marketing, Image Reconstruction and Urban Regeneration, Urban Stud, March 1993, 30, 339-349, 1993.

Recklies, D.: SWOT (-Analysis); available at: http://www. themanager.org/models/SWOT.htm (last access: 22 February 2010), 2005.
Sapountzaki, K., Wanczura, S., Casertano, G., Greiving, S., Xanthopoulos, G., and Ferrera, F.: Disconnected policies and actors and the missing role of spatial planning throughout the risk management cycle, Nat. Hazards, 59, 1445-1474, doi:10.1007/s11069-011-9843-3, 2011.

Shavelson, R. J., McDonnell, L., and Oakes, J.: Steps in designing an indicator system, Practical Assessment, Research and Evaluation, 2, available at: http://PAREonline.net/getvn.asp?v=2\{\\&\} n=12 (last access: 18 June 2010), 1991.

Slovic, P.: Trust, Emotion, Sex, Politics, and Science: Surveying the Risk-Assessment Battlefield, Risk Anal., 19, 689-701, 1999.

Stadt Dortmund: Statistikatlas 2007 - Dortmunder Stadtteile, Dortmund, available at: http://dev.statistik.dortmund.de/upload/ binarydata_do4ud4cms/25/07/14/00/00/00/140725/statistikatlas. pdf (last access: 18 June 2010), 2007.

van Asselt, M.: The complex significance of uncertainty in a risk era: logics, manners and strategies in use, in: Risk Assessment and Management 2/3/4, 125-158, 2005.

Wanczura, S.: Raumplanung und "Risk Governance" - Indikatorensystem zur Messung einer effektiven und effizienten Koordination im "Risk Governance" Prozess, Dissertation, Dortmund, 2010.

Wanczura, S., Fleischhauer, M., Greiving, S., Fourman, M., Sucker, K., and D'Andrea, A.: Analysis of recent EU, international and national research and policy activities in the field of risk governance, Del. 1.1 MIDIR Project, 2007.

UN-ISDR: Hyogo Framework for Action 2005-2015 - Building the Resilience of Nations and Communities to Disasters; Extract from the final report of the World Conference on Disaster Reduction (A/CONF.206/6), available at: http://www.unisdr.org/files/ 1037_hyogoframeworkforactionenglish.pdf, 2005.

UN-ISDR: Indicators of Progress: Guidance on Measuring the Reduction of Disaster Risks and the Implementation of the Hyogo Framework for Action, http://www.unisdr.org/files/2259_ IndicatorsofProgressHFAannexes.pdf, 2007.

UN-ISDR: Terminology on Disaster Risk Reduction, available at: http://www.unisdr.org/eng/terminology/terminology-2009-eng. html, 2009.

USAID Center for Development Information and Evaluation: Selecting performance indicators, Washington; available at: http: //pdf.usaid.gov/pdf_docs/PNABY214.pdf (last access: 20 april 2010), 1996.

Xanthopoulos, G., Xanthakis, M., and Vonitsanos, C.: Forest cover evolution in Attica and assessment of desertification trends resulting from human activities, grazing and fires, 75-91, in: Proceedings of the DeSurvey Project Workshop "Understanding, Assessing and Monitoring Desertification", edited by: Xanthopoulos, G., 19 May, 2010, Athens, Greece, Institute of Mediterranean Forest Ecosystems and Forest Products Technology, Athens, Greece, 91 pp., 2010 (in Greek).

Young, O. R.: The Institutional Dimensions of Environmental Change, Fit, Interplay, and Scale, Cambridge, Mass., London, 2002. 